AperTO - Archivio Istituzionale Open Access dell'Università di Torino

\title{
Coupling Solid-State NMR with GIPAW ab Initio Calculations in Metal Hydrides and Borohydrides
}

\section{This is the author's manuscript}

Original Citation:

Availability:

This version is available http://hdl.handle.net/2318/133378

since 2017-05-27T22:19:22Z

Published version:

DOI:10.1021/jp3126895

Terms of use:

Open Access

Anyone can freely access the full text of works made available as "Open Access". Works made available under a Creative Commons license can be used according to the terms and conditions of said license. Use of all other works requires consent of the right holder (author or publisher) if not exempted from copyright protection by the applicable law. 


\section{(3) \\ UNIVERSITÀ DEGLI STUDI DI TORINO}

This is an author version of the contribution published on:

Questa è la versione dell'autore dell'opera:

Journal of Physical Chemistry C 2013, 117 (19), 9991-9998

DOI 10.1021/jp3126895

The definitive version is available at:

La versione definitiva è disponibile alla URL:

[http://pubs.acs.org/doi/abs/10.1021/jp3126895] 


\title{
Coupling Solid-State NMR with GIPAW ab-initio Calculations in Metal Hydrides and Borohydrides
}

\author{
Federico Franco, Marcello Baricco, Michele R. Chierotti, Roberto Gobetto, Carlo Nervi* \\ Department of Chemistry and NIS, University of Turin, via P. Giuria 7, 10125 Torino, Italy \\ Keywords: GIPAW, Quantum Espresso, SSNMR, Alkaline, Alkaline-earth, Hydrides, Borohydrides.
}

\begin{abstract}
An integrated experimental-theoretical approach for the solid-state NMR investigation of a series of hydrogen-storage materials is illustrated. Seven experimental room-temperature structures of Group I and Il metal hydrides and borohydrides, namely $\mathrm{NaH}, \mathrm{LiH}, \mathrm{NaBH}_{4}, \mathrm{MgH}_{2}, \mathrm{CaH}_{2}, \mathrm{Ca}\left(\mathrm{BH}_{4}\right)_{2}$ and $\mathrm{LiBH}_{4}$, were computationally optimized. Periodic lattice calculations were performed by means of the plane-wave method, adopting the DFT Generalized Gradient Approximation (GGA) with the Perdew-Burke-Ernzerhof (PBE) functional, as implemented in the Quantum Espresso package. Projector Augmented Wave (PAW), including the Gauge-Including Projected Augmented-Wave (GIPAW) method for solid-state NMR calculations were used, adopting both Rappe-Rabe-Kaxiras-Joannopoulos (RRKJ) ultrasoft pseudopotentials and new developed pseudopotentials. Computed GIPAW chemical shifts were critically compared with the experimental ones. A good agreement between experimental and computed multinuclear chemical shifts was obtained.
\end{abstract}

\section{Introduction}

Nowadays, the main approaches for internal combustion engine replacement are based on new lithium battery technology and fuel-cell technology, mainly developed around hydrogen-based systems. ${ }^{1}$ In fact, hydrogen may be an efficient and non-polluting energy carrier, ideal for clean energy transport and storage. $^{2}$ However, the most challenging bottleneck for a widespread use of hydrogen is the development of safe and efficient storage systems, particularly for mobile applications. ${ }^{3}$ Among methods for hydrogenstorage, ${ }^{4,5}$ high-pressured gas or cryogenic liquid cannot fulfil safety and efficiency requirements. On the other hand, solid-state hydrogen storage holds great hopes to provide safe and efficient on-board hydrogen delivery. ${ }^{6}$ An intensive research is recently taking place on light metal hydrides ${ }^{7-11}$ in order to improve thermodynamic and kinetic properties of hydrogen sorption. ${ }^{12}$ Multinuclear solid-state NMR (SSNMR) is a well established technique providing sophisticated qualitative and quantitative information at local level, such as electron shielding around atom nuclei, presence of different environments and molecular mobility. ${ }^{13}$ First principle periodic calculations on condensed matter give a way to interpret and 
to predict the behaviour of new materials. The combination of these two techniques could give new insights in the field of hydrogen storage materials.

While the chemical shift calculations in solution or in the gas phase are currently considered somewhat routine, even for transition metal complexes (e.g. Refs. ${ }^{14-18}$ ), $a b$ initio calculations of NMR properties in the solid state are less developed. A first attempt to compute the magnetic shielding in molecules was performed by using localized atom-centred basis sets, based on the Molecular Orbital Theory. ${ }^{19}$ This approach, however, has soon revealed to be quite limited in the description of solid systems and computationally highly demanding. A reduction of the computational cost for the calculations was obtained introducing the pseudopotential formalism. ${ }^{20}$ This idea arose from the evidence that the core contribution to the magnetic shielding can be considered approximately as a constant, independently on chemical environments. ${ }^{21}$ Nevertheless, calculation of NMR parameters critically depends on the details of the allelectron wavefunctions in the region close to the nucleus, where pseudo-wavefunctions take an unphysical smooth behaviour. For this reason, a significant improvement of the results has been achieved in 2001, when Pickard and Mauri ${ }^{22}$ extended the Projector Augmented Wave (PAW) ${ }^{23}$ approach to the ab initio determination of the NMR parameters, allowing the reconstruction of the all-electron wavefunctions in the core region. This approach was called Gauge-Including Projected Augmented-Wave (GIPAW) and it has been recently implemented for ultrasoft pseudopotential scheme. ${ }^{24}$

First principle calculations on metal hydrides and borohydrides ${ }^{25}$ have been widely reported in recent years, e.g. $\mathrm{LiH}^{26,27} \mathrm{NaBH}_{4}{ }^{28-32} \mathrm{MgH}_{2}{ }^{33,34} \mathrm{CaH}_{2}{ }^{35,36} \mathrm{Ca}\left(\mathrm{BH}_{4}\right)_{2}{ }^{37-39}$ and $\mathrm{LiBH}_{4} \cdot{ }^{32,40-44}$ However, to our knowledge, no first principle calculations of NMR chemical shifts with the GIPAW method have been performed up to now for these compounds. So, this work is mainly focused on the computation of the NMR parameters by means of the GIPAW method in light metal hydrides and borohydrides, aiming to check the reliability of the approach for modelling of NMR spectra. The results will be of interest for the interpretation of experimental data based on unknown intermediates during hydrogen sorption reactions. ${ }^{45,46}$

\section{Experimental and Computational Methods}

All the measurements were performed using commercial samples. Compounds of $95 \%$ purity were purchased from Alfa-Aesar or Sigma-Aldrich and used as received. $\mathrm{Ca}\left(\mathrm{BH}_{4}\right)_{2}$ purchased from Sigma-Aldrich was a mixture of $\alpha$ and $\beta$ phases. For sake of comparison, pure $\alpha-\mathrm{Ca}\left(\mathrm{BH}_{4}\right)_{2}$ was also investigated. All samples were stored in a dry argon glove-box and loaded into NMR rotors while inside the glove-box. Solidstate NMR measurements were run on a Bruker Advance II 400 instrument operating at 400.23, 128.41 and 105.87 $\mathrm{MHz}$ for ${ }^{1} \mathrm{H},{ }^{11} \mathrm{~B}$ and ${ }^{23} \mathrm{Na}$, respectively. ${ }^{11} \mathrm{~B}$ and ${ }^{23} \mathrm{Na}$ spectra were recorded at room temperature at the spinning speed of $14 \mathrm{kHz}$. Cylindrical $4 \mathrm{~mm}$ o.d. zirconia rotors with sample volume of $80 \mu \mathrm{L}$ were employed. The single pulse excitation (SPE) or the DEPTH (for suppressing the probe background signal) sequences were used with a $90^{\circ}$ pulse of $3.75\left({ }^{11} \mathrm{~B}\right)$ and $2.7 \mu \mathrm{s}\left({ }^{23} \mathrm{Na}\right)$, recycle delays of $30-140\left({ }^{11} \mathrm{~B}\right)$ or $1-20 \mathrm{~s}$ 
$\left({ }^{23} \mathrm{Na}\right)$, and about 16 transients. ${ }^{11} \mathrm{~B}$ spectra of $\mathrm{LiBH}_{4}$ and $\mathrm{Ca}\left(\mathrm{BH}_{4}\right)_{2}$ (either $\alpha$ and $\beta$ phases) were acquired using the Hahn-echo pulse sequence $(\pi / 2)_{x}-\tau_{1}-(\pi)_{y}-\tau_{2}$-acq, where $\tau$ represents interpulse delays of $138 \mu$ s. ${ }^{1} \mathrm{H}$ MAS spectra were acquired in a $2.5 \mathrm{~mm}$ probe with a spinning speed of $32 \mathrm{kHz}$ using the DEPTH sequence for suppressing the probe background signal. A $90^{\circ}$ pulse of $1.8 \mu \mathrm{s}$, recycle delays of 1-60 $\mathrm{s}$, and 16 transients were used. The ${ }^{1} \mathrm{H}$, and ${ }^{11} \mathrm{~B}$ and ${ }^{23} \mathrm{Na}$ chemical shift scales were calibrated using adamantane $\left({ }^{1} \mathrm{H}\right.$ signal at $1.87 \mathrm{ppm}$ vs. TMS), and $\mathrm{NaBH}_{4}\left({ }^{11} \mathrm{~B}\right.$ signal at $-42.0 \mathrm{ppm}$ with respect to $\mathrm{BF}_{3} \cdot \mathrm{Et}_{2} \mathrm{O}^{47}$ and ${ }^{23} \mathrm{Na}$ signal at $-15.85 \mathrm{ppm}$ with respect to $\mathrm{NaCl}^{48}$ ) as external standards, respectively. Experimental ${ }^{6} \mathrm{Li}$ data were not performed by us, but they were taken from the literature ${ }^{49}$ and were referred vs $\mathrm{LiH}$.

Periodic lattice calculations were performed by means of Quantum Espresso version 4.3.2. ${ }^{50}$ The Generalized Gradient Approximation (GGA) with the Perdew-Burke-Ernzerhof (PBE) functional ${ }^{51}$ was used in all calculations. For geometry optimizations, experimental data at room temperature for $\mathrm{NaH}^{52} \mathrm{LiH}^{53}$ $\mathrm{NaBH}_{4},{ }^{54} \mathrm{MgH}_{2},{ }^{33} \mathrm{CaH}_{2}{ }^{55} \mathrm{Ca}\left(\mathrm{BH}_{4}\right)_{2}{ }^{38,56}$ and $\mathrm{LiBH}_{4}{ }^{57}$ were considered as starting structures. Calculations were performed with the variable-cell scheme, adopting the Rappe-Rabe-Kaxiras-Joannopoulos (RRKJ) ${ }^{58}$ ultrasoft pseudopotentials (USPP) (for Li with s semicore state; for B and Mg with non-linear core correction; for $\mathrm{Na}$ and Ca with $\mathrm{s}$ and $\mathrm{p}$ semicore states and non-linear core correction) available at the Quantum Espresso web site $^{59}$ (indicated as QE PP below), and the Projector Augmented Wave (PAW) ${ }^{23}$ pseudopotentials (PP) generated by the atompaw code ${ }^{60-62}$ (version 3.0.1.8). We generated Troullier-Martins norm-conserving PAW PP for $\mathrm{H}$ and $\mathrm{Ca}$, and USPP for the other atoms. For the PAW augmentation, two projectors in each angular momentum channel were used (except for $\mathrm{H}$ and Li). Vanderbilt's scheme was used to build the projectors and pseudo partial waves, whereas for sodium a RRKJ pseudization scheme was used. The generated PAW PP were also tested for transferability, checking the corresponding logarithmic derivatives. A cut-off of 60 Ry was used for structural optimization, since higher cut-off values (i.e. 200 and 120 Ry) did not affect significantly the results. The NMR chemical shifts were calculated using a 120 Ry energy cut-off by the generated PAW PP (previously used for geometry optimizations) and the available Ceresoli's PP ${ }^{63}$, via the GIPAW method. ${ }^{22}$ A 60 Ry cut-off for NMR calculations gave unsatisfactory results, but values higher than 120 Ry did not significantly improved the quality of the data. The theoretical absolute magnetic shielding $(\sigma)$ values were converted into chemical shifts $(\delta)$ relative to the absolute magnetic shielding of the reference substance $\mathrm{NaBH}_{4}$, computed at the same level (absolute shielding $\sigma=145.25$ and $146.49 \mathrm{ppm}$ for $\mathrm{B}, \sigma=588.84$ and $578.22 \mathrm{ppm}$ for $\mathrm{Na}, \sigma=30.33$ and $30.83 \mathrm{ppm}$ for $\mathrm{H}$, computed with PAW and Ceresoli's PP, respectively). For practical purposes the ${ }^{1} \mathrm{H}$ chemical shifts were reported against TMS (the experimental value of ${ }^{1} \mathrm{H}$ shift for $\mathrm{NaBH}_{4}$ vs. TMS is $-0.4 \mathrm{ppm}$ ), whereas the ${ }^{11} \mathrm{~B}$ chemical shifts were reported against $\mathrm{BF}_{3} \cdot \mathrm{Et}_{2} \mathrm{O}$ (the experimental ${ }^{11} \mathrm{~B}$ shift value for $\mathrm{NaBH}_{4} \mathrm{vs} \mathrm{BF}_{3} \cdot \mathrm{Et}_{2} \mathrm{O}$ is $-42.00 \mathrm{ppm}$ ), in a similar way as previously described. ${ }^{14}$ As for ${ }^{6} \mathrm{Li}$ nucleus in $\mathrm{LiH}$, used as a reference, we adopted the absolute shielding $\sigma=88.83$ and $\sigma=89.23 \mathrm{ppm}$, computed with PAW and Ceresoli's PP, respectively. 
The Brillouin zones were automatically sampled with the Monkhorst-Pack scheme. ${ }^{64}$ For each system we performed preliminary calculations: given a starting geometry and a fixed energy cutoff, the optimal number of k-points has been obtained by repeating simple SCF calculations with higher and higher grid mesh size until the total energy has converged within a threshold of $10^{-4} \mathrm{Ry}\left(1.3605 \cdot 10^{-3} \mathrm{eV}\right)$. By this method, applied to all the investigated compounds, the final calculated cell and NMR parameters did not change significantly. We found that the optimal effective number of k-points is inversely proportional to the volume of the cell in the real space. Geometry optimization and NMR chemical shift calculations for NaH, $\mathrm{LiH}, \mathrm{NaBH}_{4}, \mathrm{MgH}_{2}, \mathrm{CaH}_{2}, \alpha-\mathrm{Ca}\left(\mathrm{BH}_{4}\right)_{2}, \beta-\mathrm{Ca}\left(\mathrm{BH}_{4}\right)_{2}$ and $\mathrm{LiBH}_{4}$ were performed with a grid mesh of $6 \times 6 \times 6$, $8 \times 8 \times 8,4 \times 4 \times 4,6 \times 6 \times 6,4 \times 7 \times 4,3 \times 2 \times 3,3 \times 3 \times 5$ and $3 \times 6 \times 4$, respectively.

Simulations of the NMR spectra were carried out using TopSpin (Bruker) taking into account the quadrupolar interaction and anisotropic chemical shifts under MAS conditions. The tensors describing the different anisotropic interactions were all oriented in the EFG principal axis frame (PAS). The quadrupolar interaction is defined by $\mathrm{C}_{\mathrm{Q}}(\mathrm{MHz})$ and $\eta_{\mathrm{Q}}$. The chemical shift anisotropy, following the Haeberlen Convention, ${ }^{65}$ is characterized by $\delta_{\text {iso, }}$, the reduced anisotropy $\left(\delta=\delta_{\mathrm{zz}}-\delta_{\text {iso }}\right)$, the asymmetry parameter [ $\eta_{\mathrm{CSA}}=$ $\left.\left(\delta_{y y}-\delta_{x x}\right) / \delta ;(0 \leq \eta \leq+1)\right]$ (with $\left.\left|\delta_{z z}-\delta_{\text {iso }}\right| \geq\left|\delta_{x x}-\delta_{\text {iso }}\right| \geq\left|\delta_{y y}-\delta_{\text {iso }}\right|\right)$ and the three Euler angles $\{\alpha, \beta, \gamma\}$. Owing to the very small effects of the Euler angles on the spectra, they were not considered during the simulation. Thus, five independent parameters were used to characterize a single site. The simulation of the $\beta-\mathrm{Ca}\left(\mathrm{BH}_{4}\right)_{2}$ was performed on the commercial $\mathrm{Ca}\left(\mathrm{BH}_{4}\right)_{2}$ (purchased from Sigma-Aldrich) spectrum by using the values obtained from the simulation of the $\alpha$ form fixed and optimizing only the $\beta$ site.

\section{Results and Discussion}

\section{Geometry optimizations}

Calculated lattice parameters and volumes for selected metal hydrides and borohydrides are reported in Table 1. The experimental cubic $\mathrm{NaH}$, $\mathrm{LiH}$ and $\mathrm{NaBH}_{4}$, tetragonal $\mathrm{MgH}_{2}$, and orthorhombic $\mathrm{CaH}_{2}$, $\mathrm{LiBH}_{4}$ and $\alpha-\mathrm{Ca}\left(\mathrm{BH}_{4}\right)_{2}$ structures at room temperature fit reasonably well with calculated geometries.

Table 1. Comparison between the experimental and computed (by using PAW and QE PP) structural lattice parameters $(\AA)$ and volumes $\left(\AA^{3}\right)$.

\begin{tabular}{|c|c|c|c|c|c|c|c|c|c|c|c|c|c|}
\hline \multirow{2}{*}{ Sample } & \multirow{2}{*}{$\begin{array}{c}\text { Space Group } \\
\text { and Ref. }\end{array}$} & \multicolumn{4}{|c|}{ Experimental } & \multicolumn{4}{|c|}{ PAW } & \multicolumn{4}{|c|}{ QE } \\
\hline & & $a$ & b & c & V & $a$ & b & c & V & $a$ & $\mathbf{b}$ & C & $\mathbf{V}$ \\
\hline $\mathrm{NaBH}_{4}$ & $F 43 m^{54}$ & 6.138 & & & 231.2 & 6.085 & & & 225.3 & 6.124 & & & 229.7 \\
\hline $\mathrm{NaH}$ & $F m-3 m^{52}$ & 4.880 & & & 116.2 & 4.792 & & & 110.1 & 4.831 & & & 112.8 \\
\hline $\mathrm{LiH}$ & $F m-3 m^{53}$ & 4.086 & & & 68.2 & 4.062 & & & 67.0 & 3.990 & & & 63.5 \\
\hline $\mathrm{MgH}_{2}$ & $P 4_{2} / \mathrm{mnm}^{33}$ & 4.518 & & 3.021 & 61.6 & 4.519 & & 3.039 & 62.1 & 4.512 & & 3.009 & 61.3 \\
\hline $\mathrm{CaH}_{2}$ & Pnma ${ }^{55}$ & 5.960 & 3.601 & 6.817 & 146.3 & 5.907 & 3.575 & 6.772 & 143.0 & 5.891 & 3.566 & 6.754 & 141.9 \\
\hline $\mathrm{LiBH}_{4}$ & $P_{n m a}{ }^{57}$ & 7.179 & 4.437 & 6.803 & 216.7 & 7.448 & 4.398 & 6.598 & 216.1 & 7.419 & 4.382 & 6.522 & 212.0 \\
\hline$\alpha-C a\left(B H_{4}\right)_{2}$ & $\mathrm{Fddd}^{38}$ & 8.778 & 13.129 & 7.489 & 863.1 & 8.754 & 13.127 & 7.481 & 859.6 & 8.754 & 13.154 & 7.493 & 862.9 \\
\hline 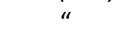 & $F 2 d d^{38,56}$ & 8.776 & 13.023 & 7.413 & 847.3 & 8.748 & 13.118 & 7.485 & 858.9 & 8.752 & 13.154 & 7.496 & 862.9 \\
\hline$\beta-\mathrm{Ca}\left(\mathrm{BH}_{4}\right)_{2}$ & $P-4^{56}$ & 6.919 & & 4.347 & 208.1 & 6.893 & & 4.362 & 207.2 & 6.951 & & 4.354 & 210.4 \\
\hline & $P 4_{2} / m^{38}$ & 6.951 & & 4.369 & 211.1 & 6.896 & & 4.363 & 207.5 & 6.951 & & 4.354 & 210.4 \\
\hline
\end{tabular}


Under ambient conditions, $\mathrm{NaH}^{52}, \mathrm{LiH}^{53}$ and $\mathrm{NaBH}_{4}{ }^{54}$ have similar $\mathrm{NaCl}$-type structures, crystallizing in the Fm-3m ( $\mathrm{LiH}$ and $\mathrm{NaH})$ and $\mathrm{F} 43 \mathrm{~m}\left(\mathrm{NaBH}_{4}\right)$ space groups. On the contrary, the unit cell of the $\alpha$-structure of $\mathrm{MgH}_{2}$, as derived from a synchrotron-radiation-based X-ray diffraction study ${ }^{33}$, is tetragonal (rutile-type structure that crystallizes in the $P 4_{2} / \mathrm{mnm}$ space group) and contains two formula-units of $\mathrm{MgH}_{2}$, in which the hydrogen atoms are crystallographically equivalent. The variable-cell optimization of these crystal structures was performed using the generated PAW PP. The results obtained, shown in Table 1, revealed to be very close not only to the experimental ones, but also to the optimized structures achieved by using the available QE PP. In addition, the structural data for $\mathrm{LiH}, \mathrm{MgH}_{2}$ and $\mathrm{NaBH}_{4}$ do not differ significantly from the results of DFT calculations already published in other papers. For example, Zhang et al. ${ }^{26}$ and van Setten et al. ${ }^{66}$ obtained fully optimized structures of LiH lattice parameters of 3.998 and $4.020 \AA$, respectively. As for $\mathrm{NaBH}_{4}$, theoretically predicted cubic geometries with lattice parameters of $6.02{ }^{30}, 6.05{ }^{31}$ and $6.14{ }^{28} \AA$ can be found in the literature. Finally, the PAW PP provided a very little overestimation of the cell volume of $\mathrm{MgH}_{2}$ (around $0.8 \%$ ) with respect to the experimental data, but a reasonable agreement appears by the comparison with other DFT-based calculations on $\mathrm{MgH}_{2}$ reported previously. ${ }^{33,34}$

The stable $\alpha$-polymorph of $\mathrm{CaH}_{2}^{55}$ (determined by neutron powder diffraction at $295 \mathrm{~K}$ ) has an orthorhombic symmetry and crystallizes in the $\mathrm{PbCl}_{2}$-type structure (space group Pnma). The $\alpha$ - $\mathrm{CaH}_{2}$ unit cell contains four formula-units, where the hydrogen atoms bonded to the same Ca atom are crystallographically not equivalent. They are located within pseudo-tetrahedral and square-pyramidal interstices (see Figure 1). As summarized in Table 1, PAW PP describe quite well the ground-state structure of $\alpha-\mathrm{CaH}_{2}$ with respect to the experimental geometry, providing less than $1 \%$ error on predicting the lattice parameters and about $2 \%$ on cell volume. A similar minimum-energy structure can be achieved by using the QE PP. In addition, there is also a good agreement with the DFT calculations previously reported. ${ }^{36}$ The reliability of the $\alpha-\mathrm{CaH}_{2}$ optimized structure can be further confirmed by looking at selected geometric details, belonging to the pseudo-tetrahedral and square-pyramid regions (see Table 2).

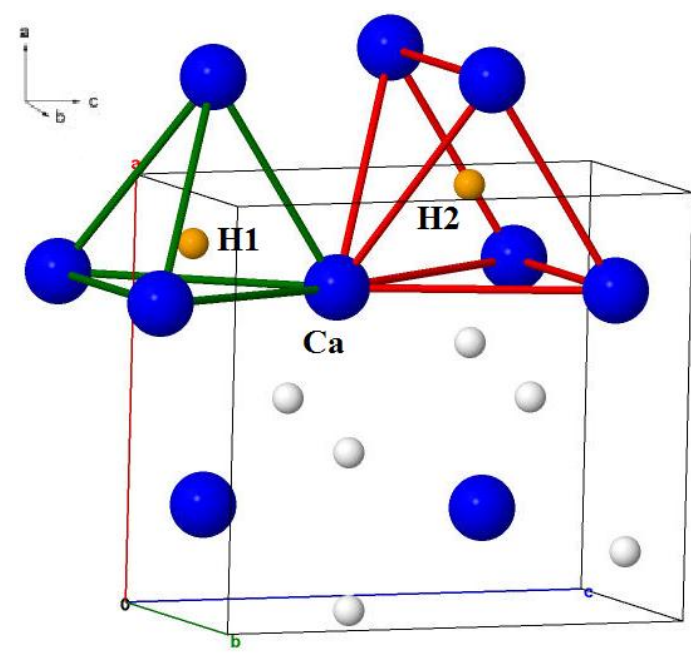


Figure 1. Minimum-energy crystal structure of $\alpha-\mathrm{CaH}_{2}$. This pictorial representation highlights the different crystallographic behaviour for $\mathrm{H} 1$ and $\mathrm{H} 2$ (both in orange): they are located in the centre of a pseudo-tetrahedron (green) and a square-pyramid (red), respectively. Atoms: $\mathrm{H}$ (white) and Ca (blue).

Table 2. Comparison between calculated and experimental $\mathrm{Ca}-\mathrm{H}$ bond lengths (mean values in $<>$ ) and selected angles in $\mathrm{H}_{1} \mathrm{Ca}_{4}$ tetrahedra and $\mathrm{H}_{2} \mathrm{Ca}_{5}$ square-pyramids. The experimental data are taken from ref. ${ }^{55}$

\begin{tabular}{|c|c|c|c|c|c|c|c|c|c|c|}
\hline \multirow{2}{*}{ Geometric unit } & \multirow{2}{*}{ Bonds and Angles } & \multicolumn{9}{|c|}{ Bond length and Angle values (Å) } \\
\hline & & \multicolumn{3}{|c|}{ Experimental } & \multicolumn{3}{|c|}{ PAW } & \multicolumn{3}{|c|}{ QE } \\
\hline $\mathrm{H} \mathrm{Ca}_{4}$ pseudo - tetrahedral & $\begin{array}{c}\mathrm{Ca}-\mathrm{H} 1(\AA) \\
<\mathrm{Ca}-\mathrm{H} 1>(\AA) \\
\mathrm{Ca}-\mathrm{H} 1-\mathrm{Ca}\left({ }^{\circ}\right)\end{array}$ & $\begin{array}{l}2.27 \\
2.28 \\
101.24\end{array}$ & $\begin{array}{l}2.32 \\
116.73\end{array}$ & 2.26 & $\begin{array}{l}2.26 \\
2.26 \\
101.29\end{array}$ & $\begin{array}{l}2.28 \\
116.70\end{array}$ & 2.24 & $\begin{array}{l}2.25 \\
2.25 \\
101.30\end{array}$ & $\begin{array}{l}2.28 \\
116.67\end{array}$ & 2.24 \\
\hline $\mathrm{H} 2 \mathrm{Ca}_{5}$ square-pyramid & $\begin{array}{c}\mathrm{Ca}-\mathrm{H} 2(\AA \AA) \\
<\mathrm{Ca}-\mathrm{H} 2>(\AA) \\
\mathrm{Ca}-\mathrm{H} 2-\mathrm{Ca}\left({ }^{\circ}\right)\end{array}$ & $\begin{array}{l}2.38 \\
2.54 \\
99.23\end{array}$ & $\begin{array}{l}2.52 \\
103.63\end{array}$ & 2.65 & $\begin{array}{l}2.39 \\
2.52 \\
99.67\end{array}$ & $\begin{array}{l}2.50 \\
104.13\end{array}$ & 2.62 & $\begin{array}{l}2.38 \\
2.52 \\
99.65\end{array}$ & $\begin{array}{l}2.50 \\
104.18\end{array}$ & 2.61 \\
\hline
\end{tabular}

A Fddd orthorhombic crystal structure has been assumed for calcium borohydride, $\alpha-\mathrm{Ca}\left(\mathrm{BH}_{4}\right)_{2}$, as determined by $\mathrm{X}$-ray synchrotron powder diffraction at $300 \mathrm{~K} \cdot{ }^{38}$ Eight formula-units of $\mathrm{Ca}\left(\mathrm{BH}_{4}\right)_{2}$ are enclosed within the unit cell, for a total of 88 atoms. X-ray diffraction experiments revealed that there are two non equivalent hydrogen atoms in the cell. The calculations performed with Quantum-ESPRESSO provided similar crystal geometries for the ground-state structures (Table 1), in good agreement with the experimental results. In fact, less than $1 \%$ errors occur for the minimum-energy structures found by using both our PAW and QE PP. Furthermore, it should be noted that the structure of $\alpha-\mathrm{Ca}\left(\mathrm{BH}_{4}\right)_{2}$, resulted from calculations with the lowest energy, is in accordance with the optimized structures obtained by other plane-wave calculations. For instance, starting from a Fddd orthorhombic geometry, a fully relaxed structure with $a=8.765, b=13.129$ and $c=7.491 \AA$ has been obtained. ${ }^{37}$ In addition, all the optimized structures are characterized by a nearly ideal tetrahedral configuration of the $\left[\mathrm{BH}_{4}\right]^{-}$units, with $\mathrm{B}-\mathrm{H}$ bond lengths approximately equal to 1.22-1.23 $\AA$. Nevertheless, some literature suggests that the $F 2 d d$ structure provided a better fit than the $F d d d$ structure for the description of the experimental room-temperature crystal structure of $\alpha-\mathrm{Ca}\left(\mathrm{BH}_{4}\right)_{2}{ }^{56}$ Therefore, we performed a full geometry optimization on $\alpha-\mathrm{Ca}\left(\mathrm{BH}_{4}\right)_{2}$, by using a F2dd starting structure; a minimum-energy geometry that is very similar to that previously obtained by adopting the Fddd structure was achieved, with lattice parameters $a=8.748, b=13.118$ and $c=7.485 \AA$. This structure also revealed to be in good agreement with other fully optimized geometries found in the literature. ${ }^{37}$ In addition to the $\alpha$-polymorph, we focused also on the crystal structure of $\beta-\mathrm{Ca}\left(\mathrm{BH}_{4}\right)_{2}$, as the commercial calcium borohydride is actually a mixture of $\alpha$ and $\beta$ phases (see also NMR data below). Two formula units of $\mathrm{Ca}\left(\mathrm{BH}_{4}\right)_{2}$ are contained within the tetragonal unit cell, for a total of 22 atoms. Synchrothron powder diffraction analysis at $305 \mathrm{~K}$ suggested that this structure crystallizes in the $P-4$ space group. ${ }^{56}$ However, more recently, the crystal structure of $\beta-\mathrm{Ca}\left(\mathrm{BH}_{4}\right)_{2}$ was refined by Noritake et al. from synchrothron $\mathrm{X}$-ray diffraction data at $433 \mathrm{~K}$, arguing that it is better described by the $P 4_{2} / \mathrm{m}$ space group. ${ }^{38}$ Four and three structurally different hydrogen atoms were found within the unit cell of the two structures, respectively. Although the two starting geometries slightly differ from each other, the same minimumenergy structure was reached employing both the sets of PP. 
The Pnma orthorhombic structure of lithium borohydride, $\mathrm{LiBH}_{4}$, was refined by Souliè et al. ${ }^{57}$ from synchrotron X-ray powder diffraction at room temperature, and it has been selected as starting geometry for variable-cell optimization. The unit cell contains four formula-units of $\mathrm{LiBH}_{4}$, and three hydrogen atoms are crystallographically not equivalent. The $\left[\mathrm{BH}_{4}\right]^{-}$units form strongly distorted tetrahedrons with $\mathrm{H}-\mathrm{B}-\mathrm{H}$ angles going approximately from $85^{\circ}$ to $120^{\circ}$. However, the calculated results do not reproduce the experimental structure. Although the cell volume is only $0.25 \%$ smaller than the experimental one, the lattice parameters of the structure with minimum of energy differ significantly from those experimentally determined by Souliè et al., ${ }^{57}$ varying in opposite directions of almost the same amount. In fact, in the optimized structure, the $a$ parameter is enlarged of about 3.75\% and the $c$ parameter (along the $z$-axis) is shortened of about $3 \%$ with respect to the corresponding experimental values. Furthermore, the calculated bond lengths and angles of the borohydride anions are similar to an ideal tetrahedron, rather than the distorted geometry observed experimentally at ambient temperature, ${ }^{54,57}$ with almost constant B-H bond lengths of 1.22-1.23 $\AA$ and H-B-H angles close to the ideal value of $109.5^{\circ}$. Quite interestingly, an analogous description of the ground-state structure of $\alpha-\mathrm{LiBH}_{4}$ resulted from other DFT plane-wave based calculations, ${ }^{41-43}$ and also from some experiments at low temperature. ${ }^{67,68}$

\section{SSNMR experiments and GIPAW calculations}

SSNMR chemical shifts $(\delta)$ of light metal hydrides and borohydrides have been measured and the results are reported in Table 3. The corresponding experimental spectra are reported in the Supporting Information (Figure SI1). Calculations of the NMR chemical shifts have been performed by means of the GIPAW $^{22}$ method, implemented as a module in the Quantum-Espresso ${ }^{50}$ distribution, on the optimized geometries previously described. For comparison and validation, the GIPAW calculations were repeated on the same structures employing the Ceresoli's QE PP. Theoretical results, summarized in Table 3 (computed chemical shift tensor values are reported in Table SI1 in the Supporting Information), are in good agreement with the experimental data. ${ }^{69}$ It should be emphasized that geometry optimizations and NMR calculations are often performed with different sets of PP. On the contrary, a single set of PP suitable to give acceptable results in both types of calculations have been used in this case. By using our PAW PP, we

found that for $\mathrm{NaH}, \mathrm{LiH}$ and $\mathrm{NaBH}_{4}$ at 60 Ry cut-off, the absolute magnetic shielding $\left({ }^{1} \mathrm{H}\right.$ and $\left.{ }^{23} \mathrm{Na}\right)$ cannot reach a convergence. On the other hand, energy cut-offs of 200 and 120 Ry provided almost the same results. Similar results were obtained by using the Ceresoli's QE PP. As a consequence, 120 Ry was selected as energy cut-off for all NMR calculations.

For the Group I hydrides (NaH and $\mathrm{LiH}$ ), the calculated ${ }^{1} \mathrm{H}$ SSNMR $\delta$ values are in good agreement with experimental data. Similar issues can be outlined for the alkali-earth hydrides $\mathrm{MgH}_{2}$ and $\mathrm{CaH}_{2}$. It is worth noting that in $\mathrm{MgH}_{2}$, a single value of the isotropic total magnetic shielding $(\sigma)$ is expected, whereas for 
$\mathrm{CaH}_{2}$ different $\sigma$ values correspond to crystallographically (and so magnetically) different hydrogen atoms. In the latter case, since the experimental spectrum shows only a single broad peak due to an intrinsic large linewidth of the proton signals in the solid state, ${ }^{13}$ the computed signals (at 4.72 and 4.64 ppm with PAW PP) are reported as a mean $\delta$ value in Table 3 (see Supporting Information). Nevertheless, these different values for $\mathrm{CaH}_{2}$ revealed to be very close to each other (i.e. under the NMR spectral resolution). In any case, for $\mathrm{MgH}_{2}$ and $\mathrm{CaH}_{2}$, calculated values close to the experimental ones were obtained by using our PAW $\mathrm{PP}$, with an overestimation for the calculated $\delta$ values of 0.4 and $0.2 \mathrm{ppm}$, respectively. The use of the Ceresoli's QE PP for GIPAW calculations on these systems brought to similar results.

Calculations of the ${ }^{1} \mathrm{H}$ SSNMR chemical shifts for borohydride systems, $\mathrm{LiBH}_{4}$ and $\mathrm{Ca}\left(\mathrm{BH}_{4}\right)_{2}$, are more challenging. This is mainly due to the presence of non equivalent hydrogen atoms in the unit cell, leading to the need of considering the average-weighted $\sigma$ value, as well as to the difficulties in their structural optimization (see above). In spite of these disadvantages, the results of computation of the chemical shift for $\mathrm{Ca}\left(\mathrm{BH}_{4}\right)_{2}$ are rather good, with a calculated $\delta$ value $0.5 \mathrm{ppm}$ smaller than the experimental one. On the contrary, a maximum error of about $1.0 \mathrm{ppm}$ occurred on the calculation of the ${ }^{1} \mathrm{H}$ SSNMR $\delta$ value of $\mathrm{LiBH}_{4}$, obtained from the weighted mean of the $\sigma$ values associated to the three non equivalent hydrogen atoms contained in the asymmetric unit. Comparable results for orthorhombic borohydride systems were obtained performing the same calculations with the Ceresoli's QE PPs. The $\mathrm{Ca}\left(\mathrm{BH}_{4}\right)_{2}$ sample purchased from Aldrich was characterized as a mixture of the $\alpha$ and $\beta$ phases (see above) as observed by the presence of a signal at $-32.5 \mathrm{ppm}$ with a shoulder at $-29.9 \mathrm{ppm}$ in the ${ }^{11} \mathrm{~B}$ MAS spectrum (Figure 2, top spectrum). By running the spectrum of pure $\alpha-\mathrm{Ca}\left(\mathrm{BH}_{4}\right)_{2}$ (Figure 2 , bottom spectrum) it was possible to correctly assign the former to the $\beta$ and the latter to the $\alpha$ form, as reported in the literature. ${ }^{46,70}$

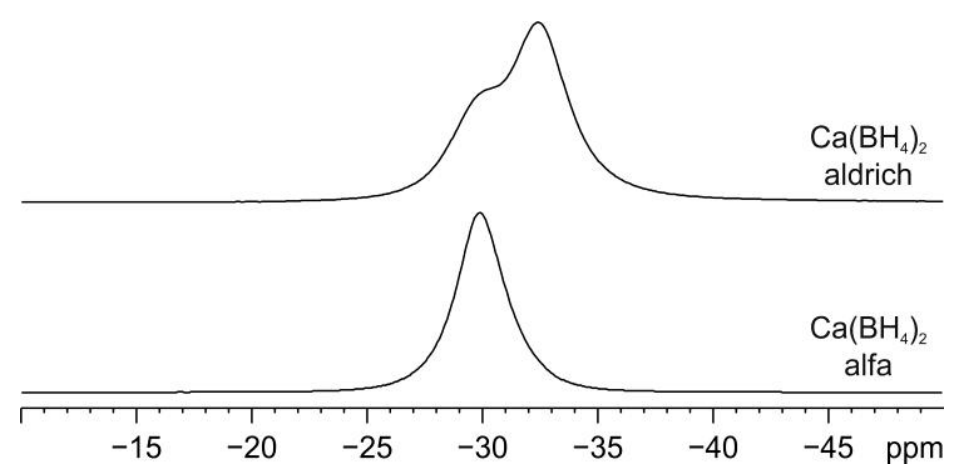

Figure 2. ${ }^{11} \mathrm{~B}$ MAS (Hahn echo) spectra (central peak) of $\alpha-\mathrm{Ca}\left(\mathrm{BH}_{4}\right)_{2}$ (bottom) and $\mathrm{Ca}\left(\mathrm{BH}_{4}\right)_{2}$ from Aldrich (top) recorded with a spinning speed of $14 \mathrm{kHz}$.

However, no differences between the commercial and pure $\alpha$ phase were observed in the experimental ${ }^{1} \mathrm{H}$ MAS spectra. Concerning $\alpha-\mathrm{Ca}\left(\mathrm{BH}_{4}\right)_{2}$, the results derived from GIPAW calculation (Table 3) performed on the optimized structure are based on the Fddd structure. In this case there are two magnetically non 
equivalent protons within the cell that produce two different $\sigma$ values; the mean $\delta$ value for ${ }^{1} \mathrm{H}$ is $-0.2 \mathrm{ppm}$. Conversely, the F2dd structure is characterized by the presence of four non equivalent hydrogen atoms in the unit cell. For this space group, QE PP provides four different $\sigma$ values in pairs very similar $(0.11,0.10$ and $0.31,-0.30 \mathrm{ppm}$, respectively) while PAW PP gives only three $\delta$ values, two of which are very close to each other $(0.04,0.03$ and $-0.37 \mathrm{ppm}$ ) (Table SI1). Nevertheless, by considering only the mean values, the same results were achieved by starting from both the Fddd and F2dd structures.

For the considered metal hydrides and borohydrides, a good correlation between ${ }^{1} \mathrm{H}$ experimental $\left(\delta_{\text {exp }}\right)$ and calculated $\left(\delta_{\text {calc }}\right)$ values was obtained for both PAW $\left(\delta_{\exp }=0.76 \cdot \delta_{\text {calc }}+0.60, R^{2}=0.986\right)$ and QE $\left(\delta_{\exp }=\right.$ $\left.0.89 \cdot \delta_{\text {calc }}+0.35, R^{2}=0.974\right)$ PP (Figure 3 ), with a mean error of about 0.48 and $0.35 \mathrm{ppm}$, respectively.

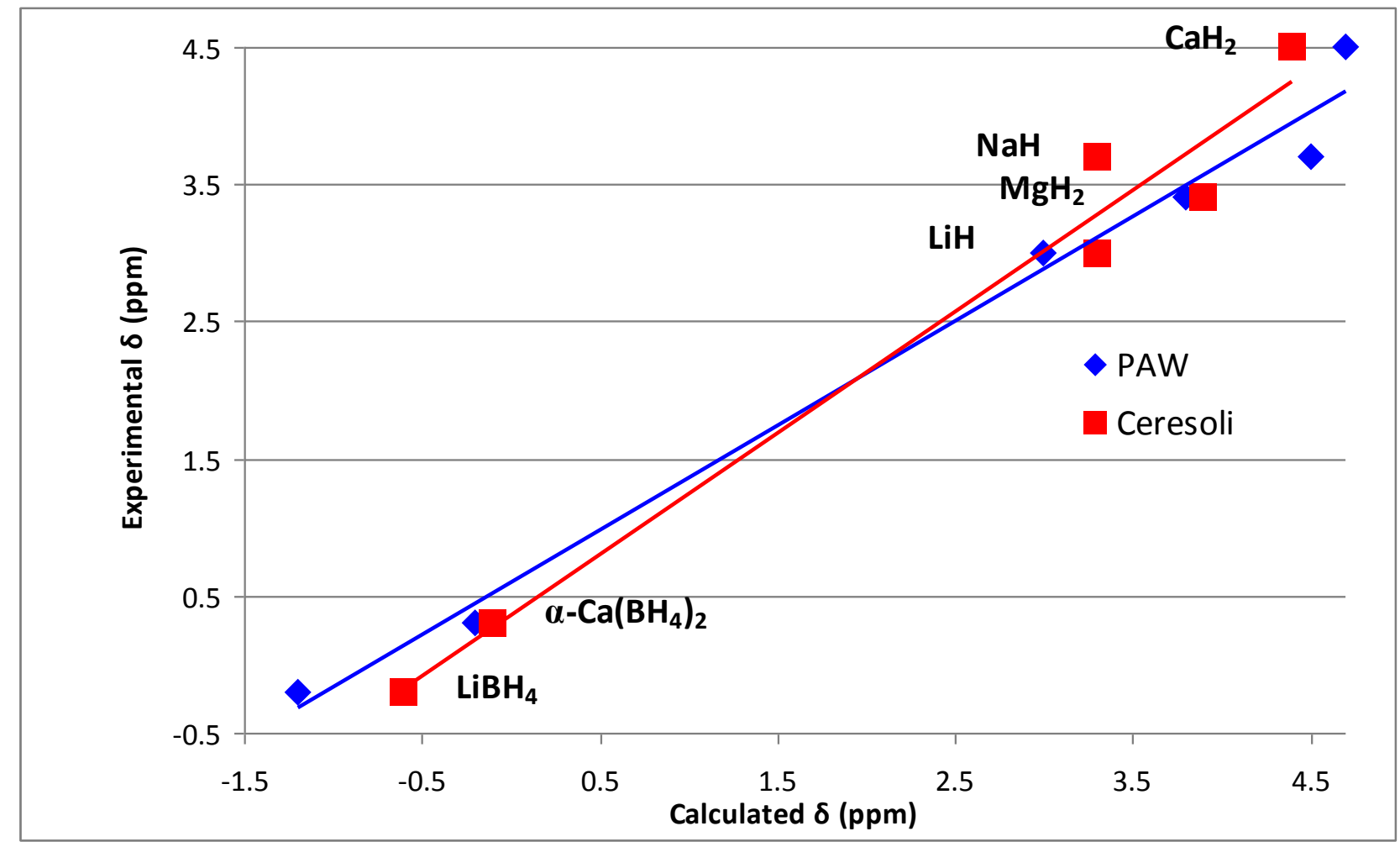

Figure 3. Experimental vs. calculated ${ }^{1} \mathrm{H}$ chemical shifts (TMS as reference).

Typically, errors of ${ }^{1} \mathrm{H} \delta$ calculations for molecules in solutions are close to $0.2 \mathrm{ppm},{ }^{71,72}$ but larger values are expected for calculations in the solid state. Taking into account the experimental uncertainties on ${ }^{1} \mathrm{H}$ SSNMR $\delta_{\text {iso }}$ values, obtained correlations can efficiently predict the experimental ${ }^{1} \mathrm{H}$ SSNMR chemical shifts. A similar procedure was adopted for the calculation of the ${ }^{6} \mathrm{Li},{ }^{23} \mathrm{Na}$ and ${ }^{11} \mathrm{~B}$ chemical shifts (see Table 3 ). From a comparison of calculated values with ${ }^{6} \mathrm{Li}$ experimental results ${ }^{49}$ on $\mathrm{LiH}$ and $\mathrm{LiBH}_{4}$, it turned out that accurate results can be obtained with Quantum-ESPRESSO, by using both our PAW PP and the GIPAW standard ones. However, while our PP tend to underestimate the ${ }^{6} \mathrm{Li}$ chemical shift of $\mathrm{LiBH}_{4}$ of $0.3 \mathrm{ppm}$, the GIPAW standards provided a value which is higher than the experimental one of the same quantity. As for ${ }^{11} B$ results, PAW PP allowed to obtain a substantial improvement in the description of the chemical shift 
values for the compounds under investigation. In particular, for ${ }^{11} \mathrm{~B}$ shift value of $\mathrm{LiBH}_{4}$, an error of less than 2 ppm occurred by employing our PAW PP, whereas the isotropic chemical shift value calculated by using QE PP was about $4.3 \mathrm{ppm}$ higher than the experimental one. A similar behaviour was achieved also about the prediction of the NMR parameters of $\mathrm{Ca}\left(\mathrm{BH}_{4}\right)_{2}$, as it can be seen in the Table 3. Moreover, our NMR computed results are able to reliably reproduce the ${ }^{11} \mathrm{~B}$ experimental spectrum of commercial $\mathrm{Ca}\left(\mathrm{BH}_{4}\right)_{2}$; in fact, as observed from experiments (see Figure 2), the GIPAW calculations confirmed that the ${ }^{11} \mathrm{~B}$ signal derived from the $\beta$-phase is about 2 ppm more shielded than the signal corresponding to the $\alpha$-phase.

Concerning the quadrupolar interaction, which is supposed to be a more accurate parameter for evaluating the quality of computational data, we observed in the ${ }^{6} \mathrm{Li},{ }^{23} \mathrm{Na}$ and ${ }^{11} \mathrm{~B}$ experimental spectra of $\mathrm{NaBH}_{4}, \mathrm{NaH}$, and $\mathrm{LiH}$ no evidences of either first or second order quadrupolar interaction, in agreement with a spherically symmetric environment of the nuclei. This has been confirmed by the negligible values obtained by the GIPAW calculation of principal EFG tensor components and the quadrupolar coupling constants (Table SI2 in the Supporting Information). However, this is not the case of ${ }^{11} \mathrm{~B}$ spectra of $\mathrm{LiBH}_{4}$ and $\mathrm{Ca}\left(\mathrm{BH}_{4}\right)_{2}$ (either $\alpha$ and $\beta$ phases) (black spectra in Figure 4) which show an extensive pattern of spinning sidebands. Simulation of the experimental spectra (red spectra in Figure 4) allowed to extract EFG tensor and quadrupolar coupling constant values together with the chemical shift tensor components, all reported in Table 4. Also for these samples, the GIPAW data reliably reproduce those obtained from the experimental spectra being in the range of commonly reported error. ${ }^{73,74}$

Table 3. Experimental and GIPAW-calculated NMR chemical shifts (ppm) with (1) generated PAW and (2) Ceresoli's QE PP. $\delta_{\text {iso }}$ values are referenced to TMS for ${ }^{1} \mathrm{H}, \mathrm{NaBH}_{4}$ for ${ }^{23} \mathrm{Na}, \mathrm{BF}_{3} \mathrm{OEt}_{2}$ for ${ }^{11} \mathrm{~B}$ and LiH for ${ }^{6} \mathrm{Li}$.

\begin{tabular}{|c|c|c|c|c|c|c|c|c|c|c|c|c|}
\hline \multirow{2}{*}{ Sample } & \multicolumn{3}{|c|}{${ }^{1} \mathrm{H}, \delta$ (ppm) } & \multicolumn{3}{|c|}{${ }^{11} \mathrm{~B}, \delta$ (ppm) } & \multicolumn{3}{|c|}{${ }^{23} \mathrm{Na}, \delta$ (ppm) } & \multicolumn{3}{|c|}{${ }^{6} \mathrm{Li}, \delta$ (ppm) } \\
\hline & Exp & (1) & (2) & Exp & (1) & (2) & Exp & (1) & (2) & Exp. $^{49}$ & (1) & (2) \\
\hline $\mathrm{NaH}$ & 3.7 & 4.5 & 3.3 & & & & 26.2 & 34.1 & 33.9 & & & \\
\hline LiH & 3.0 & 3.0 & 3.3 & & & & & & & 0.0 & 0.0 & 0.0 \\
\hline $\mathrm{MgH}_{2}$ & 3.4 & 3.8 & 3.9 & & & & & & & & & \\
\hline $\mathrm{CaH}_{2}$ & 4.5 & 4.7 & 4.4 & & & & & & & & & \\
\hline $\mathrm{LiBH}_{4}$ & -0.2 & -1.2 & -0.6 & -41.4 & -39.5 & -37.1 & & & & -1.3 & -1.6 & -1.0 \\
\hline$\alpha-\mathrm{Ca}\left(\mathrm{BH}_{4}\right)_{2}$ & 0.3 & -0.2 & -0.1 & -29.9 & -21.9 & -19.8 & & & & & & \\
\hline$\beta-\mathrm{Ca}\left(\mathrm{BH}_{4}\right)_{2}$ & 0.3 & -0.2 & 0.0 & -32.5 & -23.8 & -21.6 & & & & & & \\
\hline
\end{tabular}




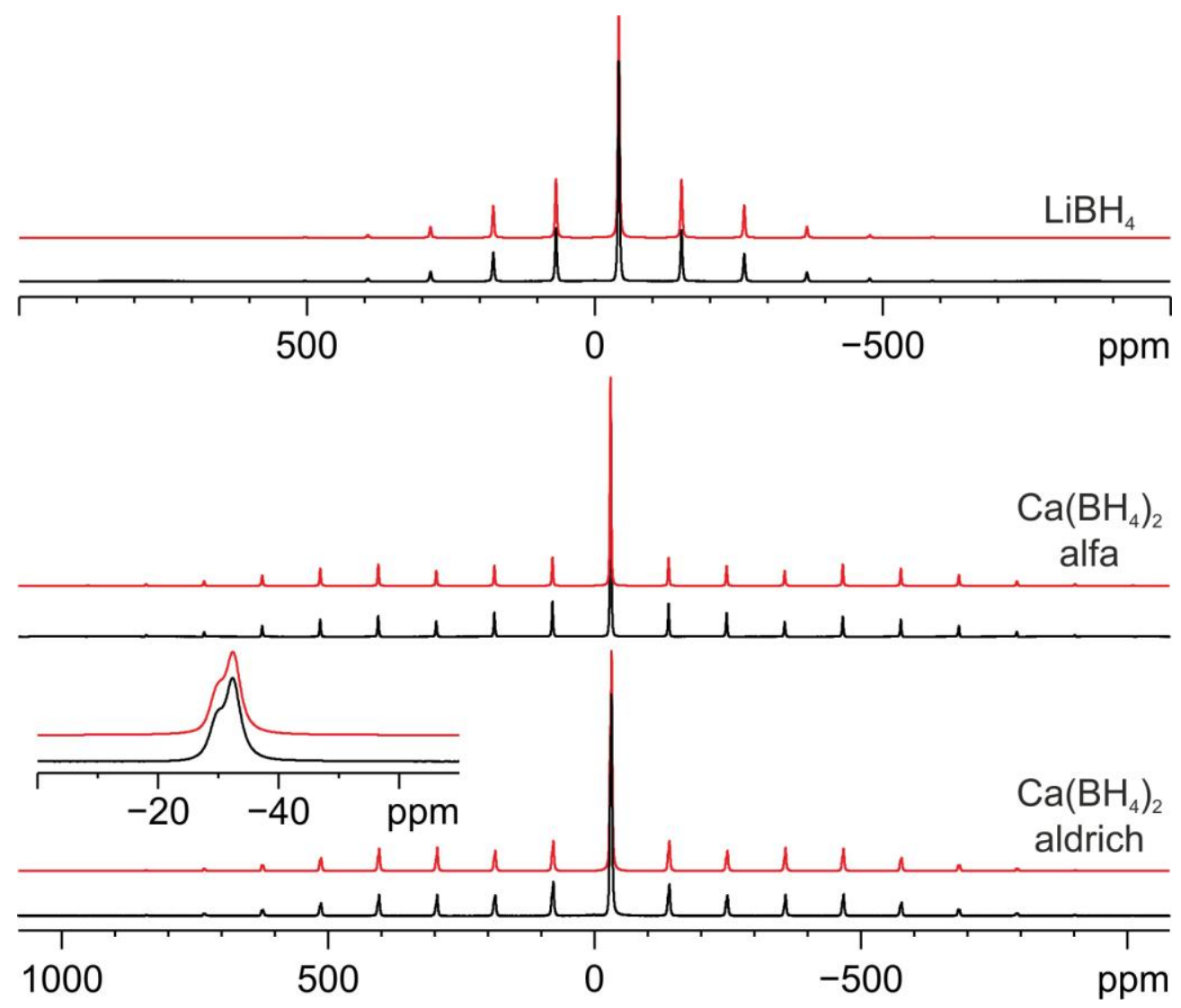

Figure 4. Experimental (black) and simulated (red) ${ }^{11} \mathrm{~B}$ MAS (Hahn echo) spectra of $\mathrm{LiBH} \mathrm{H}_{4}, \alpha-\mathrm{Ca}\left(\mathrm{BH}_{4}\right)_{2}$ and $\mathrm{Ca}\left(\mathrm{BH}_{4}\right)_{2}$ Aldrich $(\alpha+\beta$ form) recorded with a spinning speed of $14 \mathrm{kHz}$. For simulation details see Experimental and Computational Methods.

Table 4. ${ }^{11} \mathrm{~B}$ simulated and computed chemical shift anisotropy and quadrupolar values for $\mathrm{LiBH}_{4}, \alpha-\mathrm{Ca}\left(\mathrm{BH}_{4}\right)_{2}$ and $\beta-$ $\mathrm{Ca}\left(\mathrm{BH}_{4}\right)_{2}$. For simulation details see the Experimental and Computational Methods section.

\begin{tabular}{|c|c|c|c|c|c|c|c|c|c|}
\hline & & $\begin{array}{l}\boldsymbol{\delta}_{\text {iso }} \\
(\mathbf{p p m})\end{array}$ & $\begin{array}{l}\boldsymbol{\delta}_{\mathbf{x x}} \\
(\mathbf{p p m})\end{array}$ & $\begin{array}{l}\boldsymbol{\delta}_{\mathbf{y y}} \\
\mathbf{( p p m )}\end{array}$ & $\begin{array}{l}\boldsymbol{\delta}_{\mathbf{z z}} \\
(\mathbf{p p m})\end{array}$ & $\begin{array}{l}\boldsymbol{\delta}_{\text {cSA }} \\
(\mathbf{p p m})\end{array}$ & $\boldsymbol{\eta}_{\mathrm{csA}}$ & $\begin{array}{l}\mathbf{C}_{\mathbf{Q}} \\
(\mathbf{M H z})\end{array}$ & $\boldsymbol{\eta}_{\mathbf{Q}}$ \\
\hline $\mathrm{LiBH}_{4}$ & simul. & -41.1 & -38.7 & -40.2 & -44.5 & -3.3 & 0.46 & 0.10 & 0.51 \\
\hline & PAW & -39.5 & -41.9 & -40.2 & -36.3 & 3.2 & 0.55 & 0.13 & 0.64 \\
\hline$\alpha-\mathrm{Ca}\left(\mathrm{BH}_{4}\right)_{2}$ & simul. & -29.8 & -33.4 & -30.5 & -25.5 & 4.3 & 0.68 & 0.20 & 0.89 \\
\hline & PAW $^{a}$ & -21.9 & -16.3 & -20.7 & -28.7 & -6.8 & 0.64 & -0.52 & 0.89 \\
\hline$\beta-\mathrm{Ca}\left(\mathrm{BH}_{4}\right)_{2}$ & simul. & -32.5 & -32.3 & -32.4 & -32.8 & -0.3 & 0.63 & 0.18 & 0.85 \\
\hline & PAW $^{b}$ & -23.8 & -18.8 & -23.5 & -29.2 & -5.4 & 0.86 & -0.48 & 0.85 \\
\hline
\end{tabular}

${ }^{a}$ Fddd structure; ${ }^{b} P-4$ structure

\section{Conclusions}

The use of Quantum-ESPRESSO with a new set of PAW PP, generated by the atompaw code, has revealed to achieve good results for the calculation of crystal structures and SSNMR chemical shifts in selected hydrogen storage materials. Results of crystal geometries for low symmetry borohydrides $\left(\mathrm{LiBH}_{4}\right.$ and $\left.\mathrm{Ca}\left(\mathrm{BH}_{4}\right)_{2}\right)$ revealed to be in accordance with similar DFT based computational studies. Calculated SSNMR parameters (chemical shifts, quadrupolar coupling constants, and CSA) showed good correlation with 
experimental values. A maximum deviation of 1 ppm for PAW PP with respect to the experimental ${ }^{1} \mathrm{H}$ SSNMR chemical shifts was found. This value is comparable with the error obtained employing standard Ceresoli's PP. In summary, we were able to validate a new set of PAW PP, showing that the predicted SSNMR ${ }^{1} \mathrm{H},{ }^{23} \mathrm{Na}$ and ${ }^{6} \mathrm{Li}$ chemical shift values obtained by using PAW PP, are analogous to those derived by employing the standard QE PP. In addition to this, a substantial improvement of the ${ }^{11} B$ chemical shifts estimation were obtained adopting PAW PP.

\section{Acknowledgments}

The research leading to these results has received funding from the European Union's Seventh Framework Programme (FP7/2007-2013) for the Fuel Cells and Hydrogen Joint Technology Initiative under grant agreement $n^{\circ} 303428$.

The pure $\alpha-\mathrm{Ca}\left(\mathrm{BH}_{4}\right)_{2}$ was kindly provided by Prof. T. Jensen (University of Aarhus, Denmark).

\section{Author Information}

Corresponding Author

*Phone: +39 011 6707507. Fax: +39 011 6707855. E-mail: carlo.nervi@unito.it.

\section{References}

1. David, W. I. F. Effective Hydrogen Storage: a Strategic Chemistry Challenge. Faraday Discuss. 2011, 151, 399414.

2. Zuttel, A.; Borgschulte, A.; Schlapbach, L. Hydrogen As a Future Energy Carrier; Wiley-VCH: Weinheim, 2008.

3. Wang, P.; Kang, X. D. Hydrogen-Rich Boron-Containing Materials for Hydrogen Storage. Dalton Trans. 2008, (40), 5400-5413.

4. Ozturk, T.; Demirbas, A. Boron Compounds As Hydrogen Storage Materials. Energy Sources Part A-Recovery Util. Environ. Eff. 2007, 29 (15), 1415-1423.

5. Huggins, R. A. Energy Storage; Springer: New York, 2010.

6. Walker, G. Solid-State Hydrogen Storage: Materials and Chemistry. Woodhead Publishing Limited: Cambridge, 2008.

7. Boesenberg, U.; Ravnsbaek, D. B.; Hagemann, H.; D'Anna, V.; Minella, C. B.; Pistidda, C.; Van Beek, W.; Jensen, T. R.; Bormann, R.; Dornheim, M. Pressure and Temperature Influence on the Desorption Pathway of the $\mathrm{LiBH}_{4}-\mathrm{MgH}_{2}$ Composite System. J. Phys. Chem. C 2010, 114 (35), 15212-15217.

8. Borgschulte, A.; Gremaud, R.; Zuettel, A.; Martelli, P.; Remhof, A.; Ramirez-Cuesta, A.; Refson, K.; Bardaji, E.; Lohstroh, W.; Fichtner, M.; Hagemann, H.; Ernst, M. Experimental Evidence of Librational Vibrations Determining the Stability of Calcium Borohydride. Phys. Rev. B 2011, 83 (2), 024102.

9. Cerny, R.; Severa, G.; Ravnsbaek, D. B.; Filinchuk, Y.; D'Anna, V.; Hagemann, H.; Haase, D.; Jensen, C. M.; Jensen, T. R. NaSc $\left(\mathrm{BH}_{4}\right)_{4}$ : A Novel Scandium-Based Borohydride. J. Phys. Chem. C 2010, 114 (2), 13571364. 
10. Filinchuk, Y.; Richter, B.; Jensen, T. R.; Dmitriev, V.; Chernyshov, D.; Hagemann, H. Porous and Dense Magnesium Borohydride Frameworks: Synthesis, Stability, and Reversible Absorption of Guest Species. Angew. Chem. Int. Ed. 2011, 50 (47), 11162-11166.

11. Schouwink, P.; D'Anna, V.; Ley, M. B.; Daku, L. M. L.; Richter, B.; Jensen, T. R.; Hagemann, H.; Cerny, R. Bimetallic Borohydrides in the System $\mathrm{M}\left(\mathrm{BH}_{4}\right)_{2}-\mathrm{KBH}_{4}(\mathrm{M}=\mathrm{Mg}, \mathrm{Mn})$ : On the Structural Diversity. J. Phys. Chem. C 2012, 116 (20), 10829-10840.

12. Schuth, F.; Bogdanovic, B.; Felderhoff, M. Light Metal Hydrides and Complex Hydrides for Hydrogen Storage. Chem. Commun. 2004, (20), 2249-2258.

13. Chierotti, M. R.; Gobetto, R. Solid-State NMR Studies of Weak Interactions in Supramolecular Systems. Chem. Commun. 2008, (14), 1621-1634.

14. Gobetto, R.; Nervi, C.; Valfre, E.; Chierotti, M. R.; Braga, D.; Maini, L.; Grepioni, F.; Harris, R. K.; Ghi, P. Y. ${ }^{1} \mathrm{H}$ MAS, ${ }^{15} \mathrm{~N}$ CPMAS, and DFT Investigation of Hydrogen-Bonded Supramolecular Adducts Between the Diamine 1,4-Diazabicyclo-[2.2.2]Octane and Dicarboxylic Acids of Variable Chain Length. Chem. Mater. 2005, 17 (6), 1457-1466.

15. Pettinari, R.; Pettinari, C.; Marchetti, F.; Gobetto, R.; Nervi, C.; Chierotti, M. R.; Chan, E. J.; Skelton, B. W.; White, A. H. Solid-State ${ }^{15} \mathrm{~N}$ CPMAS NMR and Computational Analysis of Ligand Hapticity in Rhodium(n-Diene) Poly(Pyrazolyl)Borate Complexes. Inorg. Chem. 2010, 49 (23), 11205-11215.

16. Chierotti, M. R.; Garlaschelli, L.; Gobetto, R.; Nervi, C.; Peli, G.; Sironi, A.; Della Pergola, R. An Unusual Carbonyl Chemical Shift in a Carbonylhexairidium Cluster: A Combined Solid-State NMR and DFT Approach. Eur. J. Inorg. Chem. 2007, (22), 3477-3483.

17. Garino, C.; Ghiani, S.; Gobetto, R.; Nervi, C.; Salassa, L.; Croce, G.; Milanesio, M.; Rosenberg, E.; Ross, J. B. A. Tricarbonylchlororhenium(I) Carboxaldimine Derivatives: Synthesis, Structure, and NMR Characterization of $Z$ and $E$ Isomers. Eur. J. Inorg. Chem. 2006, (14), 2885-2893.

18. Kaupp, M.; Malkin, V. G.; Malkina, O. L.; Salahub, D. R. Calculation of Ligand NMR Chemical-Shifts in Transition-Metal Complexes Using Ab-Initio Effective-Core Potentials and Density-Functional Theory. Chem. Phys. Lett. 1995, 235 (3-4), 382-388.

19. Vaara, J. Theory and Computation of Nuclear Magnetic Resonance Parameters. Phys. Chem. Chem. Phys. 2007, 9 (40), 5399-5418.

20. Mauri, F.; Pfrommer, B. G.; Louie, S. G. Ab Initio Theory of NMR Chemical Shifts in Solids and Liquids. Phys. Rev. Lett. 1996, 77 (26), 5300-5303.

21. Gregor, T.; Mauri, F.; Car, R. A Comparison of Methods for the Calculation of NMR Chemical Shifts. J. Chem. Phys. 1999, 111 (5), 1815-1822.

22. Pickard, C. J.; Mauri, F. All-Electron Magnetic Response With Pseudopotentials: NMR Chemical Shifts. Phys. Rev. B 2001, 63 (24), 245101.

23. Blochl, P. E. Projector Augmented-Wave Method. Phys. Rev. B 1994, 50 (24), 17953-17979.

24. Yates, J. R.; Pickard, C. J.; Mauri, F. Calculation of NMR Chemical Shifts for Extended Systems Using Ultrasoft Pseudopotentials. Phys. Rev. B 2007, 76 (2), 024401.

25. Zavorotynska, O.; Corno, M.; Damin, A.; Spoto, G.; Ugliengo, P.; Baricco, M. Vibrational Properties of $\mathrm{MBH}_{4}$ and $\mathrm{MBF}_{4}$ Crystals $(\mathrm{M}=\mathrm{Li}, \mathrm{Na}, \mathrm{K})$ : A Combined DFT, Infrared, and Raman Study. J. Phys. Chem. C 2011, 115 (38), 18890-18900. 
26. Zhang, H.; Yu, Y.; Zhao, Y.; Xue, W.; Gao, T. Ab Initio Electronic, Dynamic, and Thermodynamic Properties of Isotopic Lithium Hydrides ( ${ }^{6} \mathrm{LiH},{ }^{6} \mathrm{LiD},{ }^{6} \mathrm{LiT},{ }^{7} \mathrm{LiH},{ }^{7} \mathrm{LiD}$, and $\left.{ }^{7} \mathrm{LiT}\right)$. J. Phys. Chem. Solids 2010, 71 (7), $976-$ 982.

27. Napan, R.; Blanca, E. First-Principles Studies of Lithium Hydride Series for Hydrogen Storage. Int. J. Hydrogen Energy 2012, 37 (7), 5784-5789.

28. Urgnani, J.; Torres, F. J.; Palumbo, M.; Baricco, M. Hydrogen Release From Solid State $\mathrm{NaBH}_{4}$. Int. J. Hydrogen Energy 2008, 33 (12), 3111-3115.

29. Caputo, R.; Tekin, A. Ab-Initio Crystal Structure Prediction. A Case Study: $\mathrm{NaBH}_{4}$. J. Solid State Chem. 2011, 184 (7), 1622-1630.

30. Kim, K. C.; Sholl, D. S. Crystal Structures and Thermodynamic Investigations of LiK $\left(\mathrm{BH}_{4}\right)_{2}, \mathrm{KBH}_{4}$, and $\mathrm{NaBH}_{4}$ From First-Principles Calculations. J. Phys. Chem. C 2010, 114 (1), 678-686.

31. Kim, E.; Kumar, R.; Weck, P. F.; Cornelius, A. L.; Nicol, M.; Vogel, S. C.; Zhang, J. Z.; Hartl, M.; Stowe, A. C.; Daemen, L.; Zhao, Y. S. Pressure-Driven Phase Transitions in $\mathrm{NaBH}_{4}$ : Theory and Experiments. J. Phys. Chem. B 2007, 111 (50), 13873-13876.

32. Nakamori, Y.; Miwa, K.; Ninomiya, A.; Li, H. W.; Ohba, N.; Towata, S. I.; Zuttel, A.; Orimo, S. I. Correlation Between Thermodynamical Stabilities of Metal Borohydrides and Cation Electronegativites: FirstPrinciples Calculations and Experiments. Phys. Rev. B 2006, 74 (4), 045126.

33. Vajeeston, P.; Ravindran, P.; Hauback, B. C.; Fjellvag, H.; Kjekshus, A.; Furuseth, S.; Hanfland, M. Structural Stability and Pressure-Induced Phase Transitions in $\mathrm{MgH}_{2}$. Phys. Rev. B 2006, 73 (22), 224102.

34. Cui, S. X.; Feng, W. X.; Hu, H. Q.; Feng, Z. B.; Wang, Y. X. Structural Phase Transitions in MgH $_{2}$ Under High Pressure. Solid State Commun. 2008, 148 (9-10), 403-405.

35. Pinatel, E. R.; Rude, L. H.; Corno, M.; Kragelund, M.; Ugliengo, P.; Jensen, T. R.; Baricco, M. Thermodynamic Tuning of Calcium Hydride by Fluorine Substitution. MRS Proceedings 2012, 1441, doi:10.1557/opl.2012.943.

36. Wang, K.; Du, J. L.; Kong, X. C.; Zeng, X. Q.; Zou, J. X.; Li, Z. L.; Wu, Z. Ab Initio and Thermodynamic Investigation on the Ca-H System. Int. J. Hydrogen Energy 2011, 36 (21), 13632-13639.

37. Frankcombe, T. J. Calcium Borohydride for Hydrogen Storage: A Computational Study of $\mathrm{Ca}\left(\mathrm{BH}_{4}\right)_{2} \mathrm{Crystal}$ Structures and the $\mathrm{CaB}_{2} \mathrm{H}_{\mathrm{x}}$ Intermediate. J. Phys. Chem. C 2010, 114 (20), 9503-9509.

38. Noritake, T.; Aoki, M.; Matsumoto, M.; Miwa, K.; Towata, S.; Li, H. W.; Orimo, S. Crystal Structure and Charge Density Analysis of $\mathrm{Ca}\left(\mathrm{BH}_{4}\right)_{2}$. J. Alloys Compd. 2010, 491 (1-2), 57-62.

39. Miwa, K.; Aoki, M.; Noritake, T.; Ohba, N.; Nakamori, Y.; Towata, S.; Zuttel, A.; Orimo, S. Thermodynamical Stability of Calcium Borohydride $\mathrm{Ca}\left(\mathrm{BH}_{4}\right)_{2}$. Phys. Rev. B 2006, 74 (15), 155122.

40. Corno, M.; Pinatel, E.; Ugliengo, P.; Baricco, M. A Computational Study on the Effect of Fluorine Substitution in $\mathrm{LiBH}_{4}$. J. Alloys Compd. 2011, 509, S679-S683.

41. Miwa, K.; Ohba, N.; Towata, S.; Nakamori, Y.; Orimo, S. First-Principles Study on Lithium Borohydride $\mathrm{LiBH}_{4}$. Phys. Rev. B 2004, 69 (24), 245120.

42. Lodziana, Z.; Vegge, T. Structural Stability of Complex Hydrides: LiBH ${ }_{4}$ Revisited. Phys. Rev. Lett. 2004,93 (14), 145501.

43. Tekin, A.; Caputo, R.; Zuttel, A. First-Principles Determination of the Ground-State Structure of LiBH 4 . Phys. Rev. Lett. 2010, 104 (21), 215501. 
44. Ge, Q. Structure and Energetics of $\mathrm{LiBH}_{4}$ and Its Surfaces: A First-Principles Study. J. Phys. Chem. A 2004, 108 (41), 8682-8690.

45. Minella, C. B.; Garroni, S.; Olid, D.; Teixidor, F.; Pistidda, C.; Lindemann, I.; Gutfleisch, O.; Dolores Baro, M.; Bormann, R.; Klassen, T.; Dornheim, M. Experimental Evidence of $\mathrm{Ca}\left[\mathrm{B}_{12} \mathrm{H}_{12}\right]$ Formation During Decomposition of a $\mathrm{Ca}\left(\mathrm{BH}_{4}\right)_{2}+\mathrm{MgH}_{2}$ Based Reactive Hydride Composite. J. Phys. Chem. C 2011, 115 (36), 18010-18014.

46. Minella, C. B.; Garroni, S.; Pistidda, C.; Gosalawit-Utke, R.; Barkhordarian, G.; Rongeat, C.; Lindemann, I.; Gutfleisch, O.; Jensen, T. R.; Cerenius, Y.; Christensen, J.; Dolores Baro, M.; Bormann, R.; Klassen, T.; Dornheim, M. Effect of Transition Metal Fluorides on the Sorption Properties and Reversible Formation of $\mathrm{Ca}\left(\mathrm{BH}_{4}\right)_{2}$. J. Phys. Chem. C 2011, 115 (5), 2497-2504.

47. Buhl, J. C.; Murshed, M. M. $\left(\mathrm{Na}_{4} \mathrm{BH}_{4}\right)^{3+}$ Guests Inside Aluminosilicate, Gallosilicate and Aluminogermanate Sodalite Host Frameworks Studied by ${ }^{1} \mathrm{H},{ }^{11} \mathrm{~B}$, and ${ }^{23} \mathrm{Na}$ MAS NMR Spectroscopy. Mater. Res. Bull. 2009, 44 (7), 1581-1585.

48. Pistidda, C.; Garroni, S.; Minella, C. B.; Dolci, F.; Jensen, T. R.; Nolis, P.; Bosenberg, U.; Cerenius, Y.; Lohstroh, W.; Fichtner, M.; Baro, M. D.; Bormann, R.; Dornheim, M. Pressure Effect on the $2 \mathrm{NaH}+\mathrm{MgB}_{2}$ Hydrogen Absorption Reaction. J. Phys. Chem. C 2010, 114 (49), 21816-21823.

49. Shaw, L. L.; Wan, X. F.; Hu, J. Z.; Kwak, J. H.; Yang, Z. G. Solid-State Hydriding Mechanism in the $\mathrm{LiBH}_{4}+\mathrm{MgH}_{2}$ System. J. Phys. Chem. C 2010, 114 (17), 8089-8098.

50. Giannozzi, P.; Baroni, S.; Bonini, N.; Calandra, M.; Car, R.; Cavazzoni, C.; Ceresoli, D.; Chiarotti, G. L.; Cococcioni, M.; Dabo, I.; Dal Corso, A.; de Gironcoli, S.; Fabris, S.; Fratesi, G.; Gebauer, R.; Gerstmann, U.; Gougoussis, C.; Kokalj, A.; Lazzeri, M.; Martin-Samos, L.; Marzari, N.; Mauri, F.; Mazzarello, R.; Paolini, S.; Pasquarello, A.; Paulatto, L.; Sbraccia, C.; Scandolo, S.; Sclauzero, G.; Seitsonen, A. P.; Smogunov, A.; Umari, P.; Wentzcovitch, R. M. QUANTUM ESPRESSO: a Modular and Open-Source Software Project for Quantum Simulations of Materials. J. Phys. : Condens. Matter 2009, 21 (39), 395502.

51. Perdew, J. P.; Burke, K.; Ernzerhof, M. Generalized Gradient Approximation Made Simple. Phys. Rev. Lett. 1996, $77(18), 3865-3868$.

52. Wyckoff, R. W. G. Crystal Structures 1; 2nd ed.; Interscience: New York, 1963.

53. Smith, D. K.; Leider, H. R. Low-Temperature Thermal Expansion of LiH, MgO and CaO. J. Appl. Crystallogr. 1968, 1 (4), 246-249.

54. Fischer, P.; Zuttel, A. Material Science Forum - Order-Disorder Phase Transition in $\mathrm{NaBD}_{4}$. Trans Tech Pub. LTD: Zurich-Uetikon, Switzerland, 2004; pp 287-290.

55. Alonso, J. A.; Retuerto, M.; Sanchez-Benitez, J.; Fernandez-Diaz, M. T. Crystal Structure and Bond Valence of $\mathrm{CaH}_{2}$ From Neutron Powder Diffraction Data. Z. Kristallogr. 2010, 225 (6), 225-229.

56. Filinchuk, Y.; Roennebro, E.; Chandra, D. Crystal Structures and Phase Transformations in $\mathrm{Ca}\left(\mathrm{BH}_{4}\right)_{2}$. Acta Mater. 2009, 57 (3), 732-738.

57. Soulie, J. P.; Renaudin, G.; Cerny, R.; Yvon, K. Lithium Boro-Hydride LiBH 4 . J. Alloys Compd. 2002, 346 (1-2), 200-205.

58. Rappe, A. M.; Rabe, K. M.; Kaxiras, E.; Joannopoulos, J. D. Optimized Pseudopotentials. Phys. Rev. B 1990, 41 (2), 1227-1230.

59. http://www.quantum-espresso.org/?page id=190 
60. Tackett, A. R.; Holzwarth, N. A. W.; Matthews, G. E. A Projector Augmented Wave (PAW) Code for Electronic Structure Calculations, Part II: Pwpaw for Periodic Solids in a Plane Wave Basis. Comput. Phys. Commun. 2001, 135 (3), 348-376.

61. Holzwarth, N. A. W.; Matthews, G. E.; Dunning, R. B.; Tackett, A. R.; Zeng, Y. Comparison of the Projector Augmented-Wave, Pseudopotential, and Linearized Augmented-Plane-Wave Formalisms for DensityFunctional Calculations of Solids. Phys. Rev. B 1997, 55 (4), 2005-2017.

62. Holzwarth, N. A. W.; Tackett, A. R.; Matthews, G. E. A Projector Augmented Wave (PAW) Code for Electronic Structure Calculations, Part I: Atompaw for Generating Atom-Centered Functions. Comput. Phys. Commun. 2001, 135 (3), 329-347.

63. GIPAW pseudopotentials are available at the D. Ceresoli's personal web page: https://sites.google.com/site/dceresoli/pseudopotentials

64. Monkhorst, H. J.; Pack, J. D. Special Points for Brillouin-Zone Integrations. Phys. Rev. B 1976, 13 (12), $5188-$ 5192.

65. Haeberlen, U. High Resolution NMR in Solids. Waugh, J. S., Ed.; Academic Press: New York, 1976.

66. Van Setten, M. J.; Popa, V. A.; de Wijs, G. A.; Brocks, G. Electronic Structure and Optical Properties of Lightweight Metal Hydrides. Phys. Rev. B 2007, 75 (3), 035204.

67. Hartman, M. R.; Rush, J. J.; Udovic, T. J.; Bowman, R. C.; Hwang, S. J. Structure and Vibrational Dynamics of Isotopically Labeled Lithium Borohydride Using Neutron Diffraction and Spectroscopy. J. Solid State Chem. 2007, 180 (4), 1298-1305.

68. Filinchuk, Y.; Chernyshov, D.; Cerny, R. Lightest Borohydride Probed by Synchrotron X-Ray Diffraction: Experiment Calls for a New Theoretical Revision. J. Phys. Chem. C 2008, 112 (28), 10579-10584.

69. Please note that the relative errors should be relative to the chemical shift scales: $\pm 18, \pm 200$ and \pm 180 ppm for ${ }^{1} \mathrm{H},{ }^{23} \mathrm{Na}$ and ${ }^{11} \mathrm{~B}$, respectively.

70. Kim, Y.; Hwang, S. J.; Shim, J. H.; Lee, Y. S.; Han, H. N.; Cho, Y. W. Investigation of the Dehydrogenation Reaction Pathway of $\mathrm{Ca}\left(\mathrm{BH}_{4}\right)_{2}$ and Reversibility of Intermediate Phases. J. Phys. Chem. C 2012, 116 (6), 4330-4334.

71. Kaupp, M.; Buhl, M.; Malkin, V. G. Calculation of NMR and EPR Parameters. Theory and Applications.; WileyVCH: Weinheim, 2004.

72. Gobetto, R.; Nervi, C.; Romanin, B.; Salassa, L.; Milanesio, M.; Croce, G. X-Ray Structures and Complete NMR Assignment by DFT Calculations of $\left[\mathrm{Os}(\mathrm{bpy})_{2}(\mathrm{CO}) \mathrm{Cl}_{\mathrm{PF}}\right.$ and $\left[\mathrm{Os}(\mathrm{bpy})_{2}(\mathrm{CO}) \mathrm{H}\right] \mathrm{PF}_{6} \mathrm{Complexes}_{\text {. }}$ Organometallics 2003, 22 (20), 4012-4019.

73. Laurencin, D.; Gervais, C.; Wong, A.; Coelho, C.; Mauri, F.; Massiot, D.; Smith, M. E.; Bonhomme, C. Implementation of High Resolution ${ }^{43}$ Ca Solid State NMR Spectroscopy: Toward the Elucidation of Calcium Sites in Biological Materials. J. Am. Chem. Soc. 2009, 131 (37), 13430-13440.

74. Woo, A. J.; Wasylishen, R. E. ZORA DFT Calculation of ${ }^{11}$ B Electric Field Gradient Tensor for Lithium Borates. J. Korean Magn. Reson. 2004, 8, 70-76. 
Graphic for Table of Contents

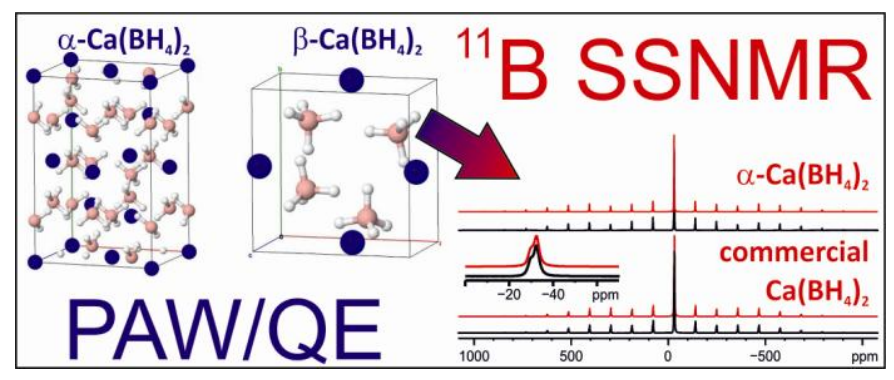




\section{Coupling Solid-State NMR with GIPAW ab-initio Calculations in Metal Hydrides and Borohydrides}

Federico Franco, Marcello Baricco, Michele R. Chierotti, Roberto Gobetto, Carlo Nervi* Department of Chemistry and NIS, University of Turin, via P. Giuria 7. 10125 Torino, Italy

Table SI1 - Computed Shielding tensors for all compounds under investigation.

$\mathrm{NaH}$

\begin{tabular}{|c|c|c|c|c|c|c|c|}
\hline & Nucleus & $\boldsymbol{\delta}_{\text {xx }}(\mathbf{p p m})$ & $\boldsymbol{\delta}_{\mathbf{y y}}(\mathbf{p p m})$ & $\boldsymbol{\delta}_{\text {zz }}(\mathbf{p p m})$ & $\boldsymbol{\delta}_{\text {iso }}(\mathbf{p p m})$ & $\boldsymbol{\delta}_{\text {cSA }}(\mathbf{p p m})$ & $\eta_{\text {cSA }}$ \\
\hline PAW & $\mathrm{Na}$ & 34.0498 & 34.0500 & 34.0503 & $\mathbf{3 4 . 1}$ & 0.0003 & 0.75000 \\
\hline & $\mathrm{H}$ & 4.5364 & 4.5364 & 4.5364 & $\mathbf{4 . 5}$ & 0.0000 & 0.00000 \\
\hline $\mathrm{QEE}$ & $\mathrm{Na}$ & 33.9062 & 33.9061 & 33.9060 & $\mathbf{3 3 . 9}$ & -0.0001 & 1.00000 \\
\hline & $\mathrm{H}$ & 3.3403 & 3.3402 & 3.3401 & $\mathbf{3 . 3}$ & -0.0001 & 1.00000 \\
\hline
\end{tabular}

$\mathrm{NaBH}_{4}$

\begin{tabular}{|c|c|c|c|c|c|c|c|}
\hline & Nucleus & $\boldsymbol{\delta}_{\mathbf{x x}}(\mathbf{p p m})$ & $\boldsymbol{\delta}_{\mathbf{y y}}(\mathbf{p p m})$ & $\boldsymbol{\delta}_{\mathbf{z z}}(\mathbf{p p m})$ & $\boldsymbol{\delta}_{\text {iso }}(\mathbf{p p m})$ & $\boldsymbol{\delta}_{\text {CSA }}(\mathbf{p p m})$ & $\eta_{\text {CSA }}$ \\
\hline PAW & $\mathrm{Na}$ & 0.0003 & 0.0003 & 0.0001 & $\mathbf{0 . 0}$ & -0.0001 & 0.00000 \\
\hline & $\mathrm{B}$ & -42.0043 & -42.0043 & -42.0044 & -42.0 & -0.0001 & 0.00000 \\
\hline & $\mathrm{H}$ & 0.7300 & 0.7300 & -2.6627 & $-\mathbf{0 . 4}$ & -2.2618 & 0.00000 \\
\hline $\mathrm{QE}$ & $\mathrm{Na}$ & 0.0000 & 0.0000 & 0.0001 & $\mathbf{0 . 0}$ & 0.0001 & 0.00000 \\
\hline & $\mathrm{B}$ & -41.9972 & -41.9972 & -41.9971 & -42.0 & 0.0001 & 0.00000 \\
\hline & $\mathrm{H}$ & 1.0976 & 1.0976 & -3.3911 & $-\mathbf{0 . 4}$ & -2.9925 & 0.00000 \\
\hline
\end{tabular}

LiH

\begin{tabular}{|c|c|c|c|c|c|c|c|}
\hline & Nucleus & $\boldsymbol{\delta}_{\mathbf{x x}}(\mathbf{p p m})$ & $\boldsymbol{\delta}_{\mathrm{yy}}(\mathbf{p p m})$ & $\boldsymbol{\delta}_{\mathbf{z z}}(\mathbf{p p m})$ & $\boldsymbol{\delta}_{\text {iso }}(\mathbf{p p m})$ & $\boldsymbol{\delta}_{\text {cSA }}(\mathbf{p p m})$ & $\boldsymbol{\eta}_{\text {csA }}$ \\
\hline PAW & $\mathrm{Li}$ & 0.0042 & 0.0042 & 0.0043 & $\mathbf{0 . 0}$ & 0.0001 & 0.00000 \\
\hline & $\mathrm{H}$ & 3.0195 & 3.0195 & 3.0196 & $\mathbf{3 . 0}$ & 0.0001 & 0.00000 \\
\hline QE & $\mathrm{Li}$ & 0.0008 & 0.0008 & 0.0008 & $\mathbf{0 . 0}$ & 0.0000 & 0.00000 \\
\hline & $\mathrm{H}$ & 3.3205 & 3.3205 & 3.3206 & $\mathbf{3 . 3}$ & 0.0001 & 0.00000 \\
\hline
\end{tabular}




\section{$\mathrm{MgH}_{2}$}

\begin{tabular}{|c|c|c|c|c|c|c|c|}
\hline & Nucleus & $\boldsymbol{\delta}_{\mathbf{x x}}(\mathbf{p p m})$ & $\boldsymbol{\delta}_{\mathbf{y y}}(\mathbf{p p m})$ & $\boldsymbol{\delta}_{\mathbf{z z}}(\mathbf{p p m})$ & $\boldsymbol{\delta}_{\text {iso }}(\mathbf{p p m})$ & $\boldsymbol{\delta}_{\text {cSA }}(\mathbf{p p m})$ & $\eta_{\text {csA }}$ \\
\hline PAW & $\mathrm{H}$ & 2.2110 & 3.5396 & 5.6467 & $\mathbf{3 . 8}$ & 1.8476 & 0.71910 \\
\hline QE & $\mathrm{H}$ & 3.9945 & 3.9736 & 3.7445 & $\mathbf{3 . 9}$ & -0.1597 & 0.13087 \\
\hline
\end{tabular}

$\mathrm{CaH}_{2}$

\begin{tabular}{|c|c|c|c|c|c|c|c|}
\hline & Nucleus & $\boldsymbol{\delta}_{\mathbf{x x}}(\mathbf{p p m})$ & $\boldsymbol{\delta}_{\mathrm{yy}}(\mathbf{p p m})$ & $\boldsymbol{\delta}_{\mathbf{z z}}(\mathbf{p p m})$ & $\boldsymbol{\delta}_{\text {iso }}(\mathbf{p p m})$ & $\boldsymbol{\delta}_{\mathrm{cSA}}(\mathbf{p p m})$ & $\eta_{\text {cSA }}$ \\
\hline PAW & $\mathrm{H} 1$ & 5.0692 & 4.9308 & 4.1700 & 4.7 & -0.5533 & 0.25012 \\
\hline & $\mathrm{H} 2$ & 4.3427 & 4.3695 & 5.2175 & 4.6 & 0.5743 & 0.04667 \\
\hline QE & $\mathrm{H} 1$ & 4.8558 & 4.6949 & 3.9462 & 4.5 & -0.5528 & 0.29108 \\
\hline & $\mathrm{H} 2$ & 3.9913 & 4.0349 & 4.9170 & 4.3 & 0.6026 & 0.07235 \\
\hline
\end{tabular}

$\mathrm{LiBH}_{4}$

\begin{tabular}{|c|c|c|c|c|c|c|c|}
\hline & Nucleus & $\delta_{x x}(p p m)$ & $\delta_{y y}(p p m)$ & $\delta_{z z}(p p m)$ & $\delta_{\text {iso }}(p p m)$ & $\delta_{\mathrm{CSA}}(\mathrm{ppm})$ & $\eta_{C S A}$ \\
\hline \multirow[t]{5}{*}{ PAW } & $\mathrm{Li}$ & -0.5566 & -1.0993 & -3.1972 & -1.6 & -1.5795 & 0.34359 \\
\hline & B & -41.9350 & -40.1831 & -36.2946 & -39.5 & 3.1763 & 0.55155 \\
\hline & $\mathrm{H} 1$ & -1.8448 & -1.3012 & -0.4408 & -1.2 & 0.7548 & 0.72019 \\
\hline & $\mathrm{H} 2$ & -0.3886 & -1.1660 & -3.1100 & -1.6 & -1.5551 & 0.49989 \\
\hline & $\mathrm{H} 3$ & 0.2941 & -0.7710 & -2.7454 & -1.1 & -1.6713 & 0.63729 \\
\hline \multirow[t]{5}{*}{ QE } & $\mathrm{Li}$ & 0.0591 & -0.5262 & -2.5863 & -1.0 & -1.5685 & 0.37316 \\
\hline & $B$ & -39.7839 & -37.9781 & -33.6075 & -37.1 & 3.5157 & 0.51364 \\
\hline & $\mathrm{H} 1$ & 0.2248 & -0.4921 & -1.2487 & -0.5 & -0.7434 & 0.96440 \\
\hline & $\mathrm{H} 2$ & 0.1806 & -0.5758 & -2.3189 & -0.9 & -1.4142 & 0.53486 \\
\hline & $\mathrm{H} 3$ & 0.8629 & -0.1872 & -1.9261 & -0.4 & -1.5093 & 0.69575 \\
\hline
\end{tabular}


$\alpha-\mathrm{Ca}\left(\mathrm{BH}_{4}\right)_{2}$ Fddd

\begin{tabular}{|c|c|c|c|c|c|c|c|}
\hline & Nucleus & $\boldsymbol{\delta}_{\mathbf{x x}}(\mathbf{p p m})$ & $\boldsymbol{\delta}_{\mathrm{yy}}(\mathbf{p p m})$ & $\boldsymbol{\delta}_{\mathbf{z z}}(\mathbf{p p m})$ & $\boldsymbol{\delta}_{\text {iso }}(\mathbf{p p m})$ & $\boldsymbol{\delta}_{\text {cSA }}(\mathbf{p p m})$ & $\eta_{\text {cSA }}$ \\
\hline PAW & $\mathrm{B}$ & -16.3295 & -20.6651 & -28.6903 & $\mathbf{- 2 1 . 9}$ & -6.7953 & 0.63803 \\
\hline & $\mathrm{H} 1$ & -1.0618 & -0.6751 & 0.5985 & $-\mathbf{0 . 4}$ & 0.9780 & 0.39541 \\
\hline & $\mathrm{H} 2$ & 1.4853 & 0.0399 & -1.4570 & $\mathbf{0 . 0}$ & -1.4797 & 0.97680 \\
\hline QE & $\mathrm{B}$ & -14.2737 & -18.6149 & -26.5024 & $\mathbf{- 1 9 . 8}$ & -6.7054 & 0.64742 \\
\hline & $\mathrm{H} 1$ & -1.0114 & -0.6521 & 0.6975 & $-\mathbf{0 . 3}$ & 1.0195 & 0.35243 \\
\hline & $\mathrm{H} 2$ & -1.3186 & 0.0839 & 1.4906 & $\mathbf{0 . 1}$ & 1.4053 & 0.99801 \\
\hline
\end{tabular}

\section{$\alpha-\mathrm{Ca}\left(\mathrm{BH}_{4}\right)_{2} F 2 d d$}

\begin{tabular}{|c|c|c|c|c|c|c|c|}
\hline & Nucleus & $\delta_{x x}(p p m)$ & $\delta_{\mathrm{yy}}(\mathrm{ppm})$ & $\delta_{\mathrm{zz}}(\mathrm{ppm})$ & $\delta_{\text {iso }}(\mathrm{ppm})$ & $\delta_{\mathrm{CSA}}(\mathrm{ppm})$ & $\eta_{C S A}$ \\
\hline \multirow[t]{5}{*}{ PAW } & B & -16.2979 & -20.6464 & -28.6557 & -21.9 & -6.7890 & 0.64052 \\
\hline & $\mathrm{H} 1$ & -1.0545 & -0.6578 & 0.5992 & -0.4 & 0.9702 & 0.40887 \\
\hline & $\mathrm{H} 2$ & -1.0536 & -0.6599 & 0.5981 & -0.4 & 0.9699 & 0.40592 \\
\hline & $\mathrm{H} 3$ & 1.4949 & 0.0500 & -1.4475 & 0.0 & -1.4800 & 0.97631 \\
\hline & $\mathrm{H} 4$ & 1.4981 & 0.0548 & -1.4435 & 0.0 & -1.4800 & 0.97522 \\
\hline \multirow[t]{5}{*}{$\mathrm{QE}$} & B & -14.2327 & -18.5897 & -26.4554 & -19.8 & -6.6961 & 0.65067 \\
\hline & $\mathrm{H} 1$ & -0.9928 & -0.6277 & 0.7076 & -0.3 & 1.0119 & 0.36081 \\
\hline & $\mathrm{H} 2$ & -0.9915 & -0.6299 & 0.7062 & -0.3 & 1.0113 & 0.35757 \\
\hline & $\mathrm{H} 3$ & -1.2980 & 0.1021 & 1.5095 & 0.1 & 1.4050 & 0.99654 \\
\hline & $\mathrm{H} 4$ & -1.2938 & 0.1068 & 1.5125 & 0.1 & 1.4040 & 0.99758 \\
\hline
\end{tabular}


$\beta-\mathrm{Ca}\left(\mathrm{BH}_{4}\right)_{2} \mathrm{P}-4$

\begin{tabular}{|c|c|c|c|c|c|c|c|}
\hline & Nucleus & $\delta_{x x}(p p m)$ & $\delta_{y y}(p p m)$ & $\delta_{\mathrm{zz}}(\mathrm{ppm})$ & $\delta_{\text {iso }}(\mathrm{ppm})$ & $\delta_{\mathrm{CSA}}(p p m)$ & $\eta_{C S A}$ \\
\hline \multirow[t]{5}{*}{ PAW } & $B$ & -18.8292 & -23.4528 & -29.2164 & -23.8 & -5.3836 & 0.85883 \\
\hline & $\mathrm{H} 1$ & 0.3514 & -0.0310 & -1.6315 & -0.4 & -1.1945 & 0.32014 \\
\hline & $\mathrm{H} 2$ & -0.5890 & -0.4871 & 0.9580 & 0.0 & 0.9974 & 0.10217 \\
\hline & $\mathrm{H} 3$ & 0.1834 & -0.2029 & -0.9103 & -0.3 & -0.6004 & 0.64344 \\
\hline & $\mathrm{H} 4$ & -0.5925 & -0.4863 & 0.9555 & 0.0 & 0.9966 & 0.10656 \\
\hline \multirow[t]{5}{*}{$\mathrm{QE}$} & B & -16.5647 & -21.3195 & -26.8205 & -21.6 & -5.2523 & 0.90529 \\
\hline & $\mathrm{H} 1$ & 0.5671 & 0.1164 & -1.2126 & -0.2 & -1.0362 & 0.43494 \\
\hline & $\mathrm{H} 2$ & -0.4438 & -0.1109 & 1.1235 & 0.2 & 0.9339 & 0.35646 \\
\hline & H3 & 0.3043 & 0.0068 & -0.4799 & -0.1 & -0.4236 & 0.70226 \\
\hline & $\mathrm{H} 4$ & -0.4462 & -0.1118 & 1.1210 & 0.2 & 0.9333 & 0.35829 \\
\hline
\end{tabular}

$\beta-\mathrm{Ca}\left(\mathrm{BH}_{4}\right)_{2} \mathrm{PH}_{2} / \mathrm{m}$

\begin{tabular}{|c|c|c|c|c|c|c|c|}
\hline & Nucleus & $\delta_{x x}(p p m)$ & $\delta_{y y}(p p m)$ & $\delta_{z z}(p p m)$ & $\delta_{\text {iso }}(p p m)$ & $\delta_{\mathrm{CSA}}(p p m)$ & $\eta_{C S A}$ \\
\hline \multirow{4}{*}{ PAW } & $B$ & -18.7948 & -23.4389 & -29.1659 & -23.8 & -5.3660 & 0.86546 \\
\hline & $\mathrm{H} 1$ & -0.5557 & -0.4522 & 0.9907 & 0.0 & 0.9964 & 0.10387 \\
\hline & $\mathrm{H} 2$ & 0.2172 & -0.1684 & -0.8776 & -0.3 & -0.6013 & 0.64124 \\
\hline & $\mathrm{H} 3$ & 0.3898 & 0.0052 & -1.6038 & -0.4 & -1.2009 & 0.32027 \\
\hline \multirow[t]{4}{*}{$\mathrm{QE}$} & $B$ & -16.5704 & -21.3429 & -26.8098 & -21.6 & -5.2354 & 0.91158 \\
\hline & $\mathrm{H} 1$ & -0.4479 & -0.1156 & 1.1169 & 0.2 & 0.9324 & 0.35638 \\
\hline & $\mathrm{H} 2$ & 0.5667 & 0.1144 & -1.2244 & -0.2 & -1.0433 & 0.43353 \\
\hline & $\mathrm{H} 3$ & 0.3000 & 0.0013 & -0.4857 & -0.1 & -0.4242 & 0.70409 \\
\hline
\end{tabular}


Table SI2 - Computed EFG tensors for all compounds under investigation.

\begin{tabular}{|c|c|c|c|c|c|c|c|c|c|}
\hline & Isotope & Spin & $\begin{array}{c}\text { Quadrupole } \\
\text { Moment (Q) } \\
\left(10^{-30} \mathrm{~m}^{2}\right)\end{array}$ & Sample & $V_{x x}$ & $\mathrm{~V}_{\mathrm{yy}}$ & $\mathrm{V}_{\mathrm{zz}}$ & $\mathrm{C}_{\mathrm{Q}}(\mathrm{MHz})$ & $\eta_{Q}$ \\
\hline \multirow{13}{*}{ PAW } & ${ }^{23} \mathrm{Na}$ & $3 / 2$ & 10.4 & $\mathrm{NaBH}_{4}$ & 0.0000 & 0.0000 & 0.0000 & 0.0000 & 0.00000 \\
\hline & & & & $\mathrm{NaH}$ & 0.0000 & 0.0000 & 0.0000 & 0.0000 & 0.00000 \\
\hline & ${ }^{11} \mathrm{~B}$ & $3 / 2$ & 4.059 & $\mathrm{NaBH}_{4}$ & 0.0000 & 0.0000 & 0.0000 & 0.0000 & 0.00000 \\
\hline & & & & $\mathrm{LiBH}_{4}$ & -0.0026 & -0.0116 & 0.0141 & 0.1348 & 0.63560 \\
\hline & & & & Fddd $\alpha-\mathrm{Ca}\left(\mathrm{BH}_{4}\right)_{2}$ & 0.0030 & 0.0513 & -0.0542 & -0.5170 & 0.89094 \\
\hline & & & & $F 2 d d \alpha-\mathrm{Ca}\left(\mathrm{BH}_{4}\right)_{2}$ & 0.0030 & 0.0513 & -0.0543 & -0.5177 & 0.89120 \\
\hline & & & & $P-4 \beta-\mathrm{Ca}\left(\mathrm{BH}_{4}\right)_{2}$ & 0.0039 & 0.0468 & -0.0507 & -0.4839 & 0.84605 \\
\hline & & & & $\mathrm{P} 4_{2} / \mathrm{m} \beta-\mathrm{Ca}\left(\mathrm{BH}_{4}\right)_{2}$ & 0.0039 & 0.0469 & -0.0507 & -0.4837 & 0.84806 \\
\hline & ${ }^{6} \mathrm{Li}$ & 1 & -0.0808 & $\mathrm{LiH}$ & 0.0000 & 0.0000 & 0.0000 & 0.0000 & 0.0000 \\
\hline & & & & $\mathrm{LiBH}_{4}$ & 0.0015 & 0.0053 & -0.0069 & 0.0013 & 0.55849 \\
\hline & ${ }^{7} \mathrm{Li}$ & $3 / 2$ & -4.01 & $\mathrm{LiH}$ & 0.0000 & 0.0000 & 0.0000 & 0.0000 & 0.0000 \\
\hline & & & & $\mathrm{LiBH}_{4}$ & 0.0015 & 0.0053 & -0.0069 & 0.0646 & 0.55849 \\
\hline & ${ }^{25} \mathrm{Mg}$ & $5 / 2$ & 19.94 & $\mathrm{MgH}_{2}$ & -0.0342 & -0.0602 & 0.0943 & 4.4195 & 0.27553 \\
\hline \multirow[t]{13}{*}{ QE } & ${ }^{23} \mathrm{Na}$ & $3 / 2$ & 10.4 & $\mathrm{NaBH}_{4}$ & 0.0000 & 0.0000 & 0.0000 & 0.0000 & 0.00000 \\
\hline & & & & $\mathrm{NaH}$ & 0.0000 & 0.0000 & 0.0000 & 0.0000 & 0.00000 \\
\hline & ${ }^{11} \mathrm{~B}$ & $3 / 2$ & 4.059 & $\mathrm{NaBH}_{4}$ & 0.0000 & 0.0000 & 0.0000 & 0.0000 & 0.00000 \\
\hline & & & & $\mathrm{LiBH}_{4}$ & -0.0021 & -0.0101 & 0.0123 & 0.1170 & 0.65390 \\
\hline & & & & Fddd $\mathrm{Ca}\left(\mathrm{BH}_{4}\right)_{2}$ & 0.0018 & 0.0247 & -0.0264 & -0.2522 & 0.86426 \\
\hline & & & & $F 2 d d \mathrm{Ca}\left(\mathrm{BH}_{4}\right)_{2}$ & 0.0018 & 0.0248 & -0.0266 & -0.2537 & 0.86107 \\
\hline & & & & $P-4 \beta-\mathrm{Ca}\left(\mathrm{BH}_{4}\right)_{2}$ & -0.0013 & -0.0180 & 0.0193 & 0.1842 & 0.86609 \\
\hline & & & & $P 4_{2} / m \beta-\mathrm{Ca}\left(\mathrm{BH}_{4}\right)_{2}$ & -0.0014 & -0.0180 & 0.0194 & 0.1849 & 0.85764 \\
\hline & ${ }^{6} \mathrm{Li}$ & 1 & -0.0808 & $\mathrm{LiH}$ & 0.0000 & 0.0000 & 0.0000 & 0.0000 & 0.0000 \\
\hline & & & & $\mathrm{LiBH}_{4}$ & 0.0017 & 0.0038 & -0.0055 & 0.0010 & 0.38732 \\
\hline & ${ }^{7} \mathrm{Li}$ & $3 / 2$ & -4.01 & $\mathrm{LiH}$ & 0.0000 & 0.0000 & 0.0000 & 0.0000 & 0.0000 \\
\hline & & & & $\mathrm{LiBH}_{4}$ & 0.0017 & 0.0038 & -0.0055 & 0.0521 & 0.38732 \\
\hline & ${ }^{25} \mathrm{Mg}$ & $5 / 2$ & 19.94 & $\mathrm{MgH}_{2}$ & -0.0087 & -0.0597 & 0.0683 & 3.2010 & 0.74635 \\
\hline
\end{tabular}


Figure SI1- Experimental ${ }^{1} \mathrm{H},{ }^{11} \mathrm{~B}$ and ${ }^{23} \mathrm{Na}$ SSNMR spectra of all the studied samples .

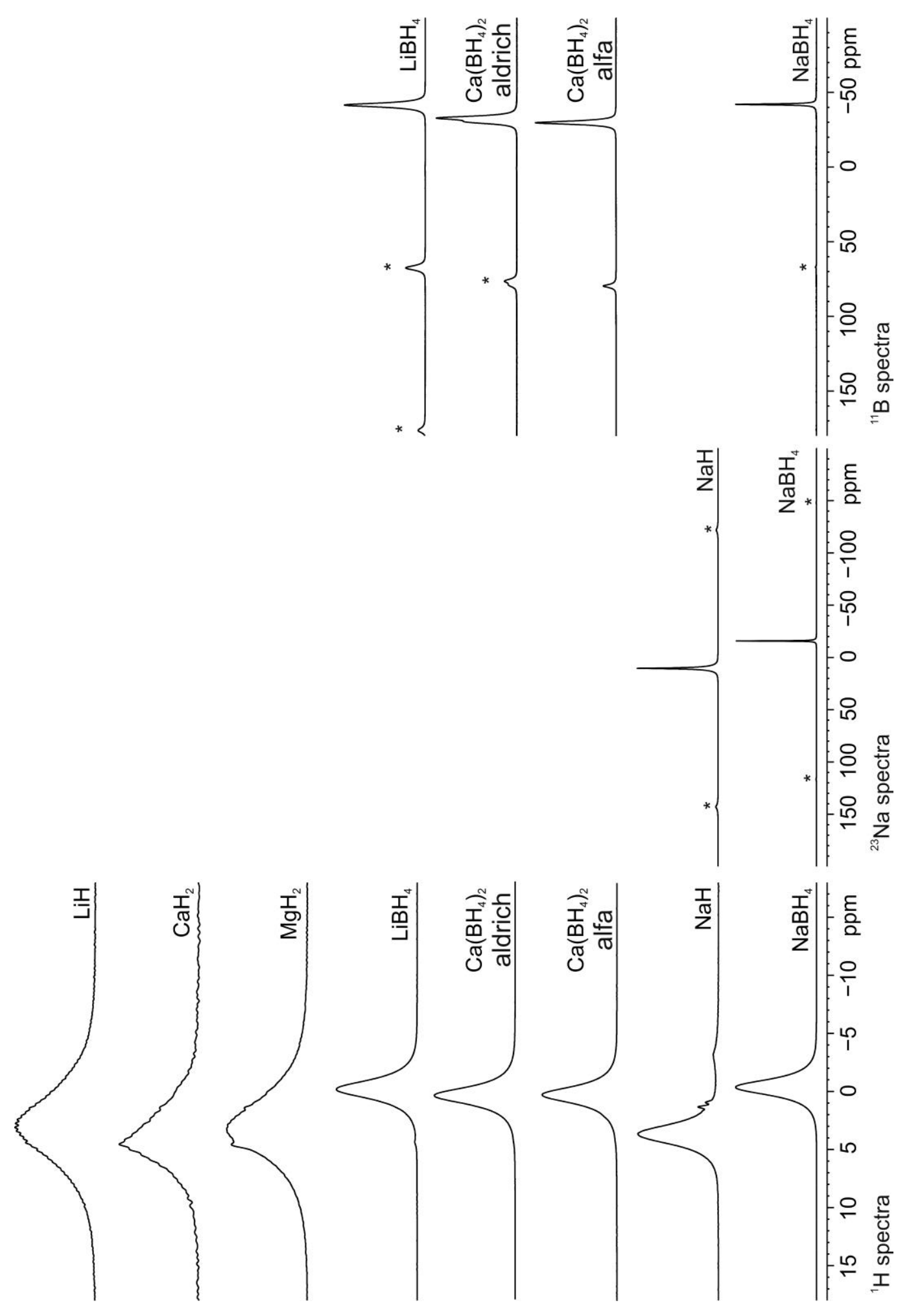

